\title{
اتجاهات وتفضيل معلِّمي المرحلة المتوسطة نحو رعاية الطلبة الموهوبين في مدارس الموهبة في دولة الكويت
}

\author{
حامد جاسم السهو \\ أستاذ مساعد- تخصص تربية خاصة- كلية التربية الأساسية- الكويت \\ dr.alsahou@hotmail.com \\ زينب عبدالرضيا عباس \\ أستاذ مشارك- تخصص تربية خاصة- كلية التربية الأساسية- الكويت \\ dr.zaenab@gmail.com
}

هدفت هذه الدراسة إلى قياس اتِّجاهات معلِّمي ومعلمات المرحلة المتوسطة نحو رعاية الموهوبين في مدارس الموهبة، وردود أفعالهم حول المّال

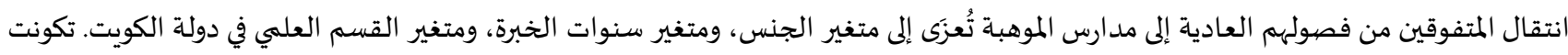

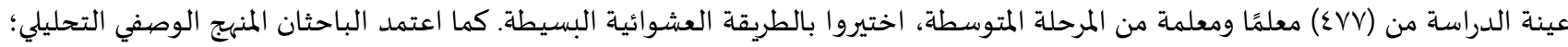

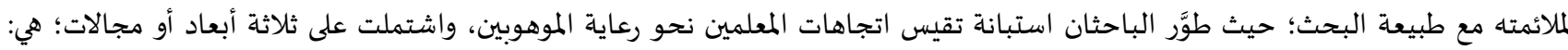

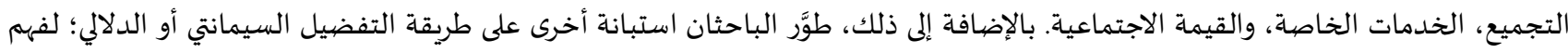

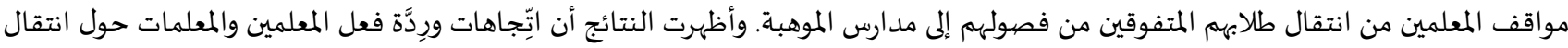

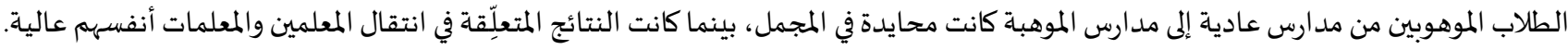

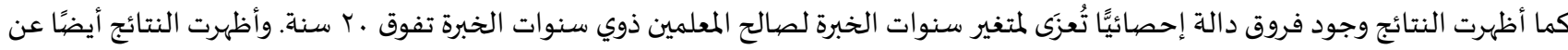

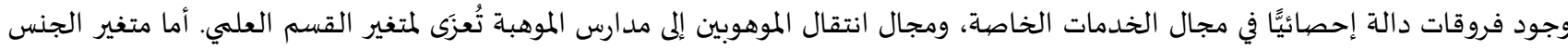

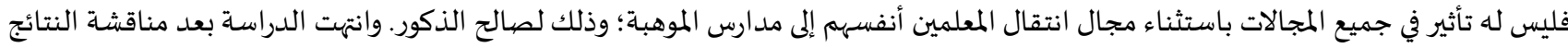
إلى اقتراح بعض التوصيات، وطرح بعض الأفكار البحثية في هذا المجال.

الكلمات المفتاحية: اتجاهات؛ الطلبة الموهوبون؛ مدارس الموهبة؛ التجميع؛ الخدمات الخاصة؛؛ القيمة الاجتماعية.

\section{(c) (7)}

المقدِّمة:

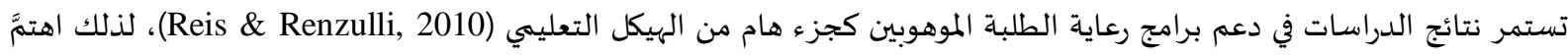

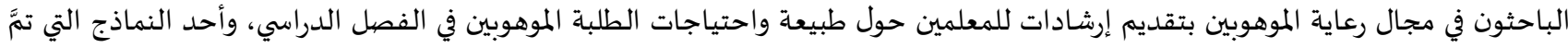

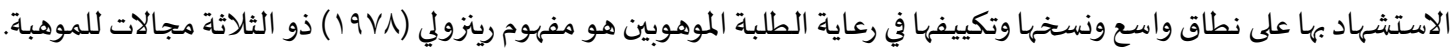

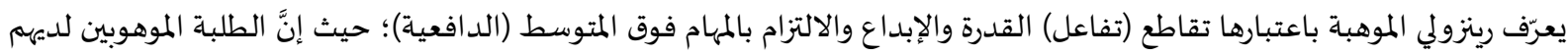

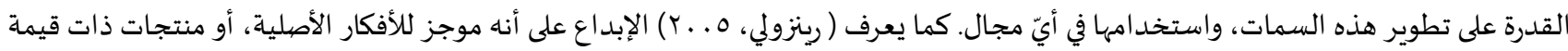
في مجال معين. وبعدها قام رينزولي (Renzulli, 2005) بتحديث وتوضيح نموذجه؛ حيث إنَّ نموذج رينزولي له تأثير على نماذج أخرى لمفهوم الموهبة التي

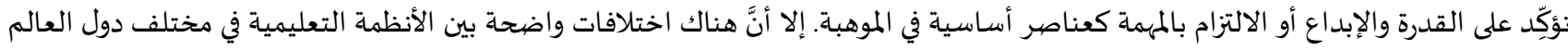

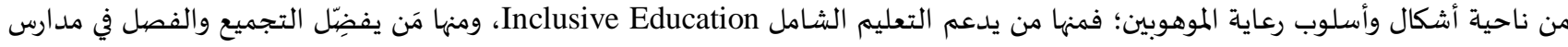

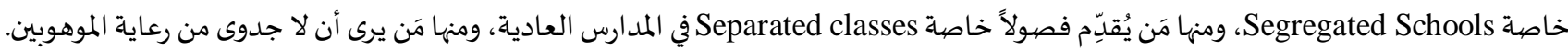




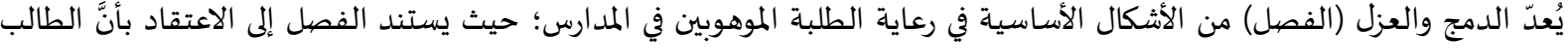

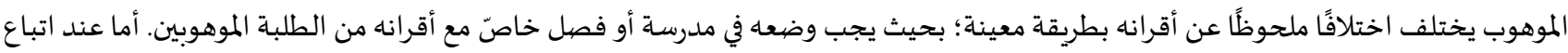

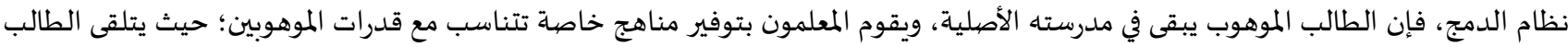

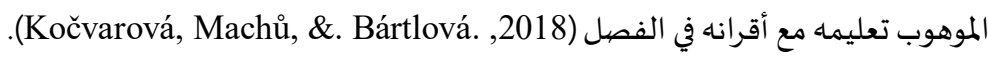

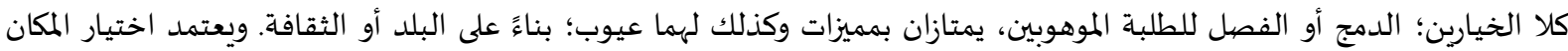

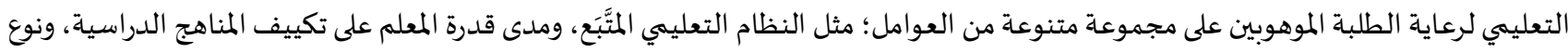

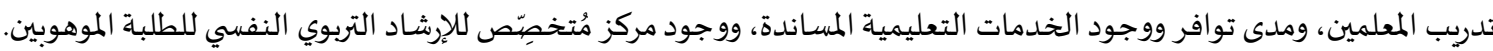

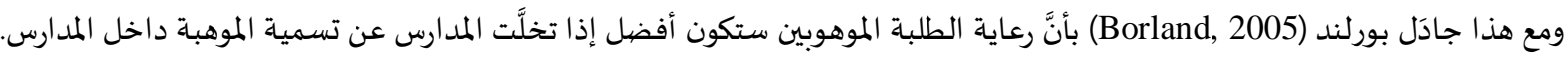

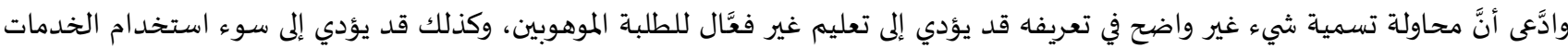

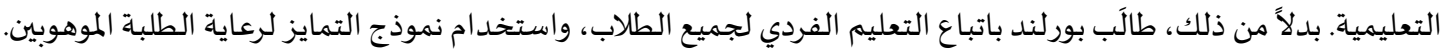

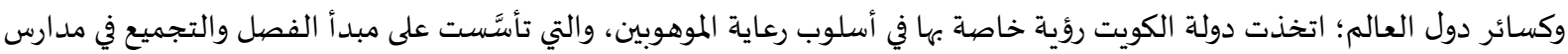

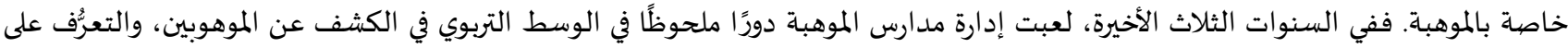
قدراتهم، ونقلهم إلى مدارس الموهبة.

أولاً: رعاية الموهوبين في دولة الكويت إنداء

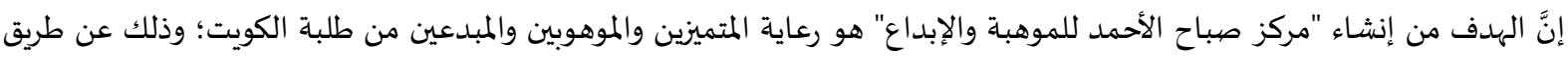

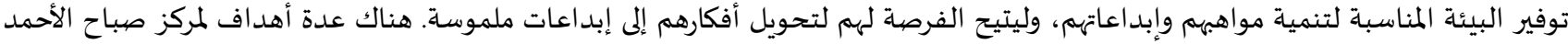
للموهبة والإبداع، منها: رعاية الطلبة الموهوبين الكويتيين. تعزيز ونشر مفهوم الإبداع. الكشف عن المبدعين واحتضان إبداعاتهم. تطوير الخبرات والمهارات الخاصة بالموهوبين والمبدعين. استثمار الإبداعات الوطنية (مركز صباح الأحمد للموهبة والإبداع 19 ـ. (ج).

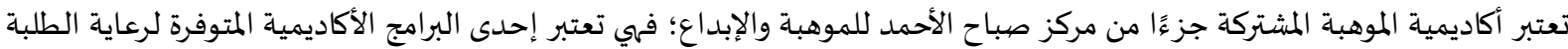

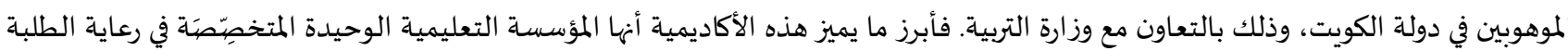

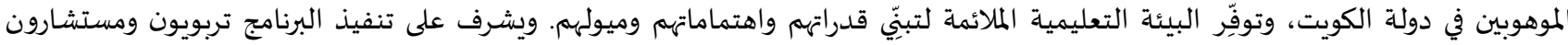

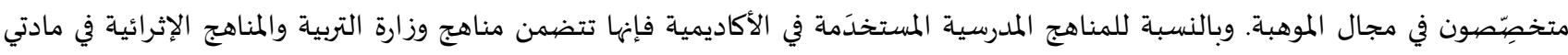
الرياضيات والعلوم، بالإضافة إلى تقديم أنشطة وتطبيقات خلال المان العام الدراسي.

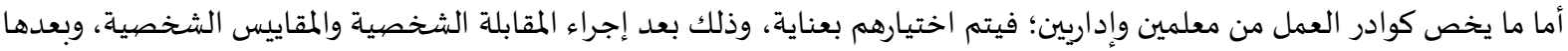

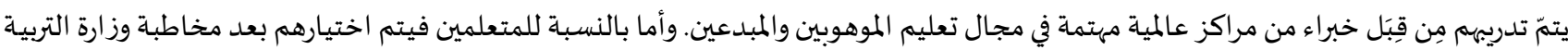

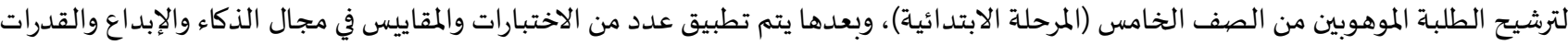
المدرسية والسمات السلوكية. يتم قبول الطلبة للبرنامج وفق المعايير التالية: التحصيل الدراسي: ويُقاس بدلالة معدل الفصل الدراسي الأول في الصف الخامس الابتدائي، وخاصة مواد الرياضيات والعلوم واللغة العربية. السمات والخصائص السلوكية للموهوبين والمبدعين: وتُقاس باستخدام معيار تقدير الخصائص السلوكية مِن قِبَل المُعلّم. الاستعداد الأكاديمي:ويُقاس من خلال الأداء في اختبارات الاستعداد الأكاديمي للتفكير اللفظيّ والكمِيّي.

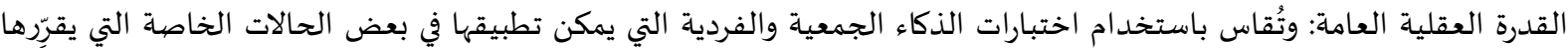

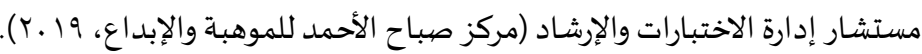

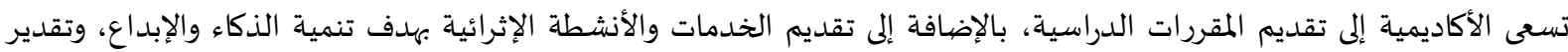

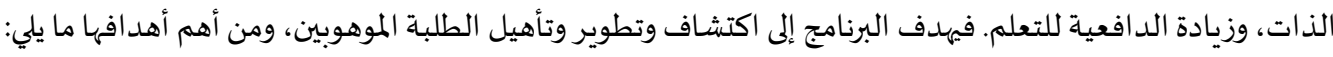
الكشف عن الطلبة الموهوبين. 


\section{تطوير برامج إثرائية. \\ تطوير برامج تربوية وإرشادية مساندة.}

التعاون بين مركز صباح الأحمد للموهبة والإبداع ووزارة التربية والهيئات الإدارية والتعليمية في المدارس وأولياء أمور الطلبة الموهوبين.

تنمية مهارات التواصل لدى الطلبة الموهوبين باستخدام اللغتين العربية والإنجليزية. تنمية مهارات التفكير الناقد والتفكير الإبداعي، ومهارات حلّ المشكلات واتخاذ القرار لدى المتعلمين. إعداد الكوادر التعليمية والإدارية للتعامل مع الطلبة الموهوبين. تقديم خدمات إرشادية نفسية وخدمات اجتماعية للطلبة الموهوبين وأولياء أمورهم. تقديم خدمات صحية (مركز صباح الأحمد للموهبة والإبداع، 19 • Yم).

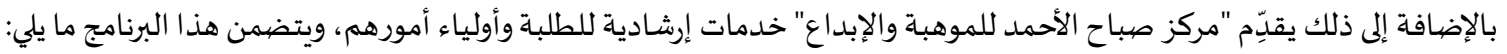
عقد جلسات فردية للإرشاد النفسي لجميع الطلبة. عقد جلسات جماعية للإرشاد النفسي لجميع الطلبة. عقد جلسات للإرشاد العائلي لأولياء أمور الطلبة الموهوبين.

تدريب وإعداد الأخصائيين النفسيين في مدارس الموهبة. إجراء الدراسات العلمية بهدف تطوير الخدمات المقدَّمة في المركز. إعداد نموذج البروفايل النفسي/ الأكاديمي لكلِّ طالب. تطوير وتقنين الاختبارات المستخدَمة للطلبة الموهوبين. تقديم برنامج الإرشاد المهني الموجهة للطلبة الموهوبين (مركز صباح الأحمد للموهبة والإبداع، 19 ـ ب).

ثانيًا: اتجاهات المعلمين نحو تعليم الطلبة الموهوبين

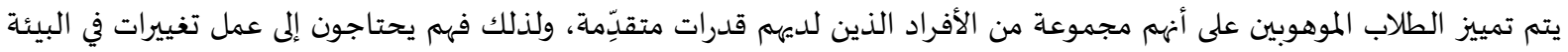
المدرسية لتلبية احتياجاتهم، مثل المناهج التعليمية وسلوكيات المعلمين (Reis \& Renzulli, 2010). لذلك نجد أنَّ نجاح العملية التعليمية للطلبة الموهوبين يعتمد بدرجة كبيرة على مدى معرفة ومدى تدريب المعلمين، إلى جانب الاتجاهات الإيجابية للمعلمين نحو رعاية الطلبة الموهوبين.

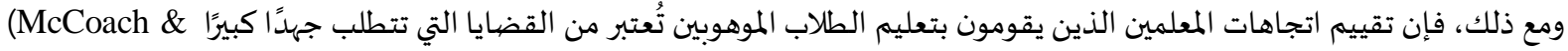
( كما أظهرت نتائج الدراسات متعددة الثقافات اختلافات تتعلّق باتجاهات المعلمين نحو رعاية الطلبة الموهوبين في كلّ بلد؛ حيث بيَّنت

نتائج هذه الدراسات أن الاختلافات الثقافية تلعب دورًا هامًا في تكوين اتجاهات المعلمين نحو رعاية الطلبة الموهوبين (Ramos,2010).

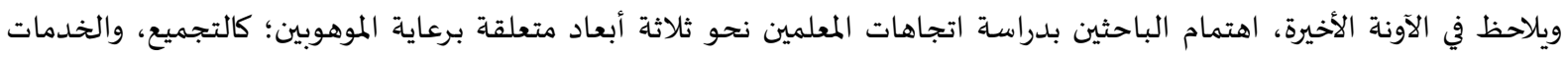

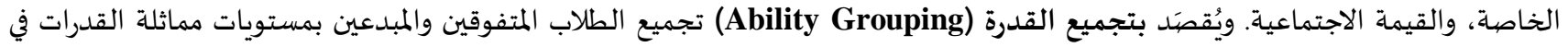

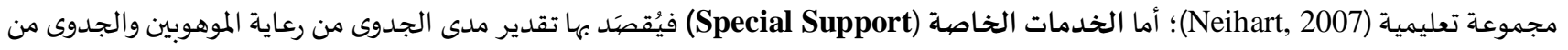
نتائجها المرجوة على المجتمع في المستقبل(Lassig, 2009) ؛ أما القيمة الاجتماعية (Social Value)فهي المبادئ التي تحدد كيفية مشاركة

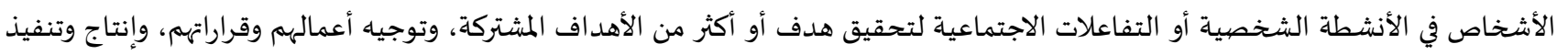

أفكار جديدة ذات صلة(Kornblum, 1994)

وبمراجعة الأدبيات، اتضح أيضًا أن هناك بعض الدراسات التي تهتم بقياس اتجاهات المعلمين نحو رعاية الطلاب الموهوبين باستخدام

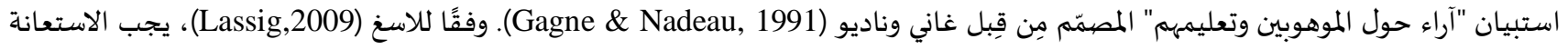

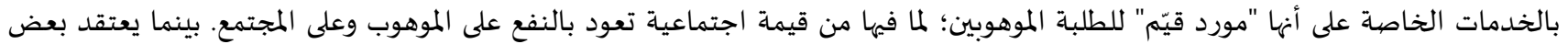

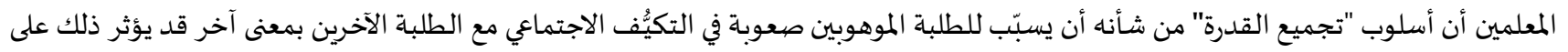
الاحتياجات العاطفية والاجتماعية للطلبة الموهوبين. ومع هذا يتفق المعلمون على أن المدارس يجب أنس أن تقدّم خدمات تعليمية خاصية كالخدمات

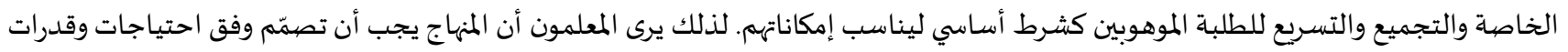

$$
\text { وميول الطلبة الموهوبين (الشمري، } 17 \text {. (Y). }
$$

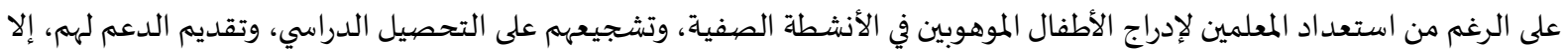
أنَّ المعلمين يعتبرون أنفسهم أقل استعدادًا لإجراء تغييرات خاصة في التدراج التطبيقات التعليمية، أو استخدام مواد تعليمية مختلفة، أو إنشاء بيئة فصل 
دراسي خاصية لتلبية احتياجات الطلبة الموهوبين، وحتى المعلمين ذوي الخبرة يجدون صعوبة في إعداد تجارب خاصية للطلبة الموهوبين بسبب افتقارهم إلى المعرفة والخبرة في هذا المجال (Riley, 2011; Smith, 2006). فدون توفير الدعم المنتظم فإن المعلمين المكلفين بتعليم الطلبة الموهوبين يقصرون في محاولتهم لمتابعة المناهـج الدراسية، وتوفير المعرفة التي تحفّز الطلاب الموهوبين على التعلم (McCoach \& Siegle,2007).

ثالثًا: الدراسـات السـابقة اطلع الباحثان على عددٍ من البحوث والدراسات السـابقة المتعلِّقة باتجاهات المعلمين نحو تعليم الطلبة الموهوبين، وفيما يلي عرض لأهم

الدراسات ذات الصلة بالموضوع:

Kočvarová, ) بسبب التغييرات في التشريعات التربوية للنظام التعليمي في جمهورية التشيك، أجرى كل من كوكفروف ومشيو وبرتلافا (Machů, \& Bártlová, 2018 الدمج) في النظام التعليمي لجمهورية التشيك. اشتملت عينة الدراسة على 1 ـ11 معلم يعملون في المرحلة الثانوية، والذين قاموا باستكمال استبانة

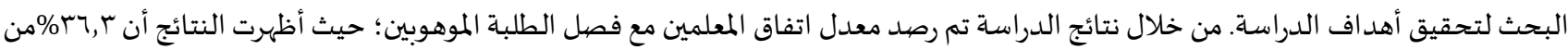

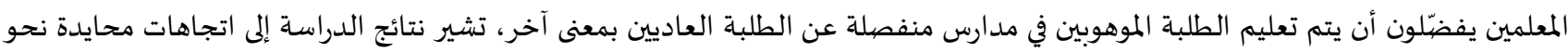

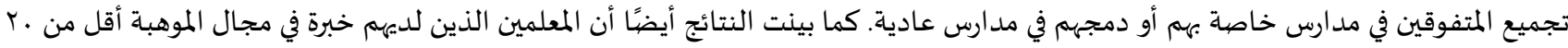

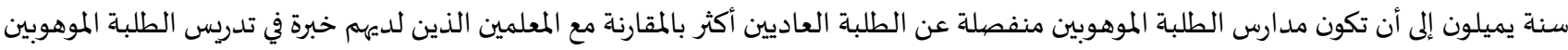

تفوق ·r سنة

هدفت دراسة روسل (Russell, 2018) لتكوين فهم أعمق لاتجاهات معلمي المدارس الثانوية الموهوبين نحو تعليم الطلبة الموهوبين. وأجرى

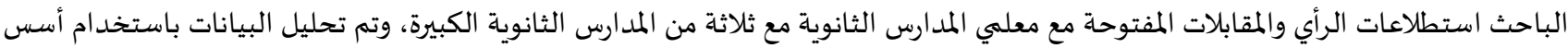

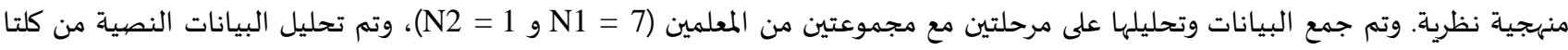
المرحلتين بشكل منفصل، ومن ثم التحقق من صحتها باستخدام عمليات المقارنة المستمرة. وأشـارت النتائج إلى الحاجة إلى أن يتم توضيح مفهوم الموهبة مرهية

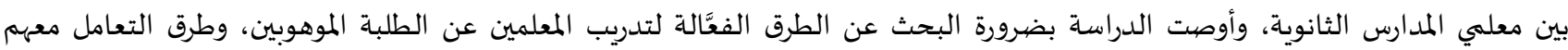
وتدريسهم.

أما الغرض من دراسة كلّ من أبو وأكانت وقوكدر (Abu, Akkanat \& Gökdere, 2017) فهو استكشاف وجهات نظر معلمي الفصول الدراسية نحو تعليم الطلبة الموهوبين في الفصول الدراسية العادية؛ حيث تكونت عينة الدراسة من عشرة معلماسية وفوكين بالمدرسة الابتدائية، وكان لديهم طلاب موهوبون في فصولهم. تم جمع البيانات من خلال مقابلات شبه منظمة وتحليلها وصفيًّا في برنامج حزمة QSR N-Vivo، وأظهرت النتائج أن

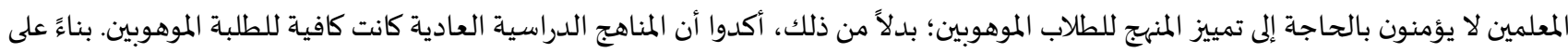
النتائج، من الواضح أن المعلمين يحتاجون إلى التدريب على التعليم المتمايز للطلبة الموهوبين والاستراتيجيات والمناهج حول كيفية تعليم الطلبة الموهوبين. ومن أبرز ما جاء في توصيات الدراسة هو التحقيق في اتجاهات المعلمين تجاه الطلاب الموهوبين في الفصول الدونين الدراسية العادية والمتخصصية؛

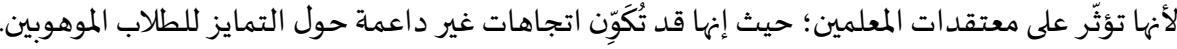

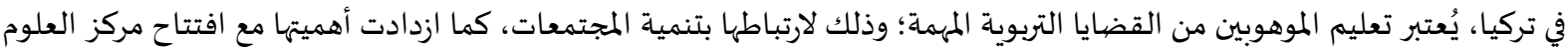
والفن. لذلك هدفت دراسة تورتب وكنت (Tortop \& Kunt, 2013) إلى معرفة اتجاهات معلمي المرحلة الابتدائية نحو تعليم الطلبة الموهوبين. تكونت

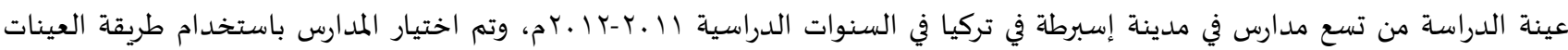

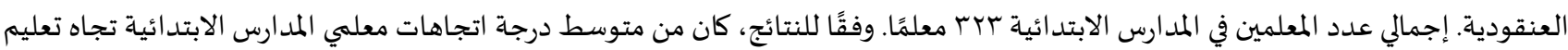

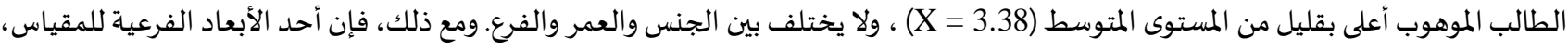

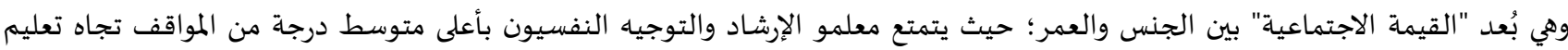

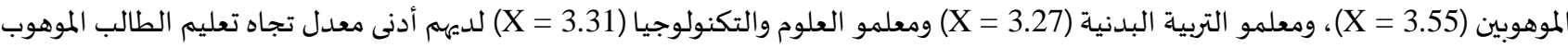
على التوالي.

تهدف دراسة أوزكان (Ozcan,2016) إلى تحديد العلاقة بين اتجاه المشاركين بالدراسة نحو تعليم الطلبة الموهوبين. تكونت عينة الدراسة

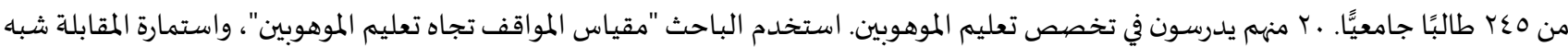
المهيكلة التي طوَّرها الباحث كأداة لجمع البيانات. تظهر النتائج أن المعلمين لديهم مواقف إيجابية تجاه تعليم الطلاب الموهوبين. كما أظهرت النتائج أنها

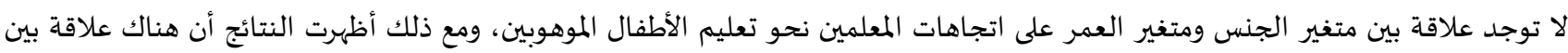
تخصُّص المعلمين واتجاهاتهم نحو تعليم الطلاب الموهوبين. 
كان الهدف من دراسة كرجن وجورس وبوريك (Krijan, Jurče and Borić,2015) هو دراسة اتجاهات معلمي المدارس الابتدائية تجاه الطلاب الموهوبين وتجاه بعض المناهج التعليمية المستخدمة لهم (التسارع وتجميع القدرات) في كرواتيا. وتم التحقيق كذلك من العلاقة بين مواقف المعلمعلمين وبعض الخصائص الاجتماعية والديموغرافية للمعلمين. شارك في الدراسة و. ج معلمين في المدارس الابتدائية. تم استخدام استبانة غاني وناديو ) لقياس اتجاهات المعلمين نحو الطلاب الموهوبين وتعليمهه. أظهرت النتائج أن المعلمين لديهم موقف محايد تجاهي الموهوبين، مما يعني أن المعلمين يدركون احتياجات الموهوبين ودعمهم وقيمتهم الاجتماعية، ولكنهم يفتقرون إلى أن يحددوا موقفههم تجاه الأحكام

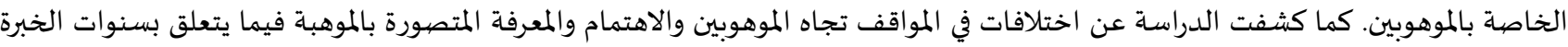

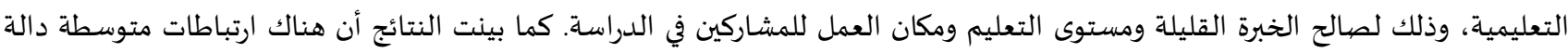
إحصائيًا بين التجميع والقيمة الاجتماعية والخدمات الخاصة، كمدا أن هناك ارتباطًا صغيرًا بين رغبة المعلمين في تدريس الطلبة الفائقين من خلال الخدمات الخاصة.

دراسة بيرسون (Persson,2014) كان الغرض منها: دراسة تصورات معلمي المدارس فيما يتعلق بتعليم الطلاب الموهوبين في البيئات

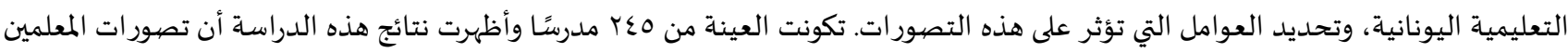

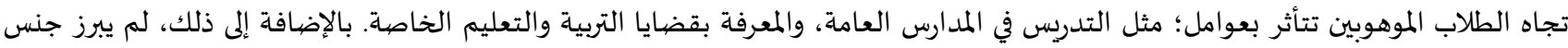
المعلمين كعامل ينتج عنه نتائج مختلفة، ولم يتم تقديم نتائج مختلفة لمعلمي المدارس الابتدائية والثانوية. حسين خان زاده ويغانه وطاهر (Hosseinkhanzadeh, Yeganeh, \& Taher,2013) كان الغرض من دراستهم هو التحقيق في مواقف

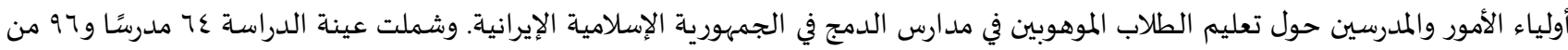

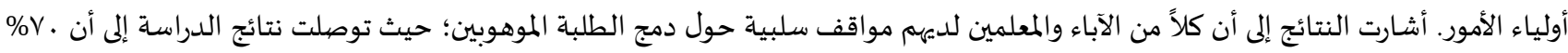

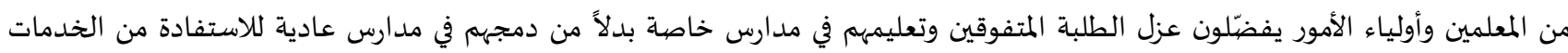
الخاصة؛؛ سواء التربوية أو التكنولوجية.

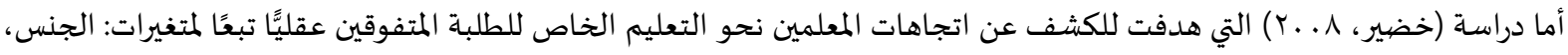

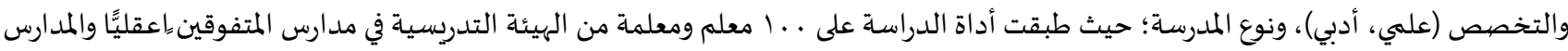

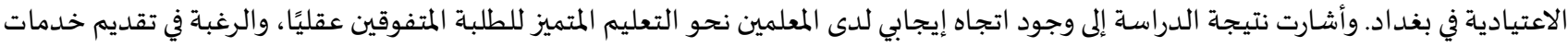

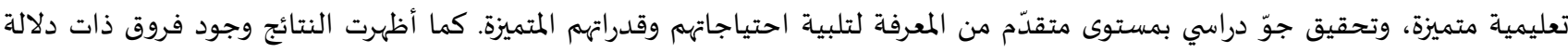

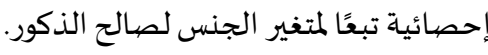

التعقيب على الدراسات السابقة:

من خلال استعراض الدراسات السابقة، يتبين ارتباطها بموضوع الدراسة الحالية؛ وذلك من خلال قياس اتجاهات المعلمين نحو رعاية

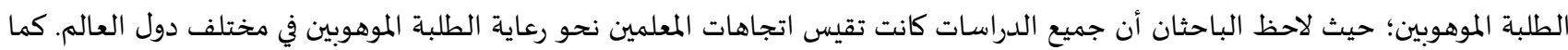

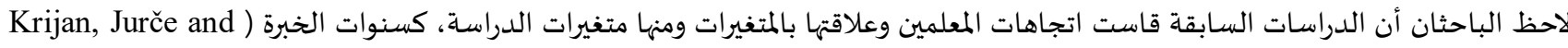
خضير Ozorić , 2015; Kočvarová, Machů, \& Bártlová, 2018

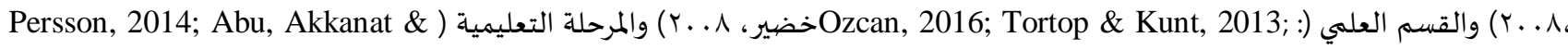

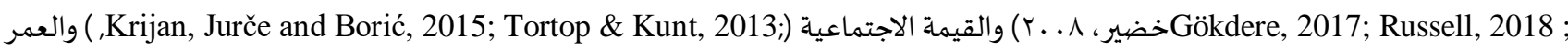
Hosseinkhanzadeh,Yeganeh, \& Taher, 2013; Krijan, Y. . 1 والخدمات الخاصة (خضير، (Ozcan, 2016; Tortop \& Kunt, 2013 ) كما لاحظ الباحثان افتقار المجتمع البحثي العربي لدراسات في هذا المجال، ولهذا السبب اعتمدت هذه الدراسـة في إطارها النظري على الأدب التربوي الغربي والدراسات السابقة الأجنبية. في حين استفادت الدراسة الحالية من الدراسات السابقة في بناء جانبها النظري، وبناء أدوات الدراساة، فكان تركيز هذه الدراسـة على قياس

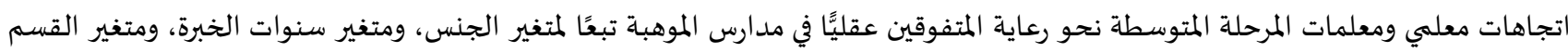
العلمي في دولة الكويت.

مشكلة الدراسـة:

على الرغم من أن المعلمين غالبًا لا يشاركون بشكل مباشر في وضع القوانين ورسم السياسات المتعلقة برعاية الموهوبين؛ سواء من خلال

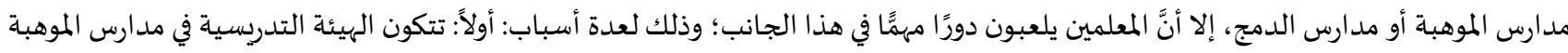

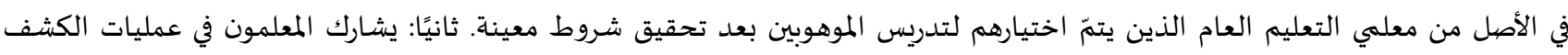




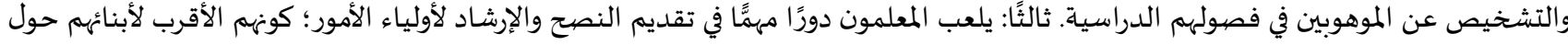

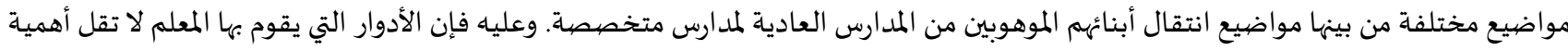

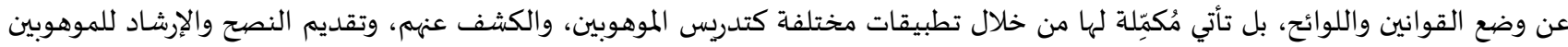

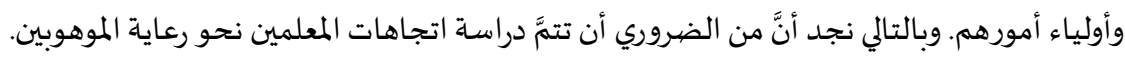

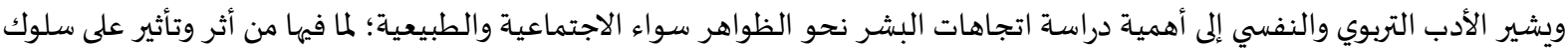

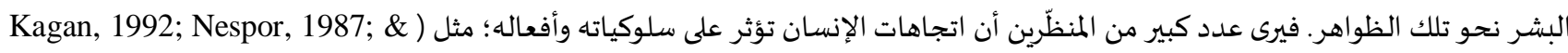

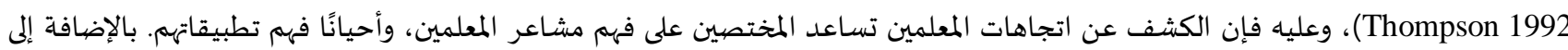

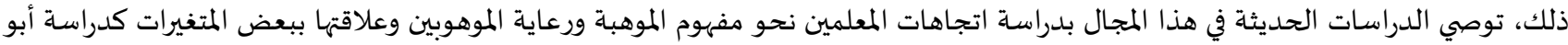
وأكانت وقوكدر (Abu, Akkanat \& Gökdere, 2017)، ودراسة روسل (Russell, 2018)، ودراسة كوكفروف ومشيو وبرتلافا ( Kočvarová,

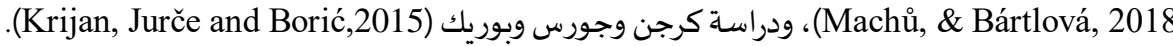

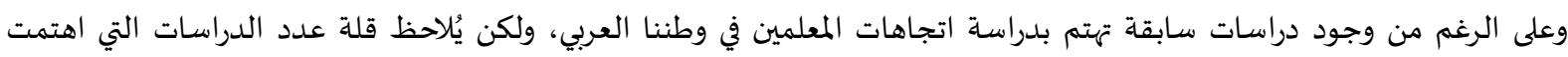

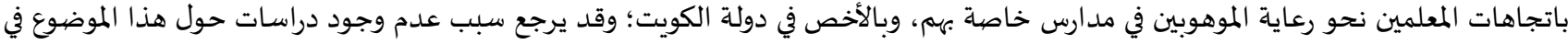

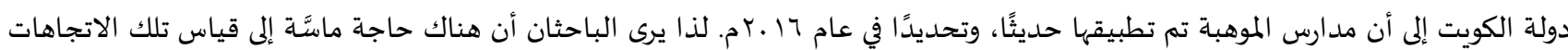

ل الإجابة عن الأسئلة التالية.

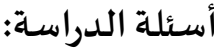

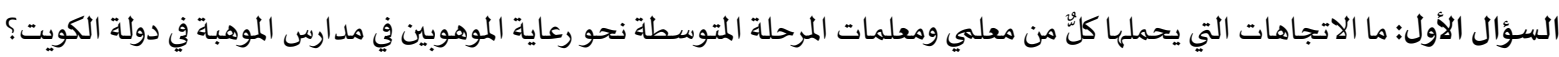

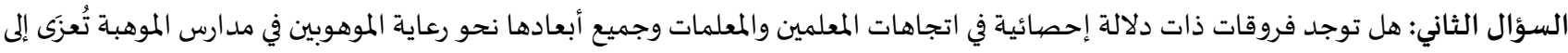

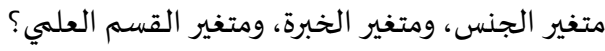
السؤال الثالث: هل توجد علاقات ارتباطية ذات دلالة إحصائية بين الأبعاد التي تكونت منها اتجاهات المعلمين مع بعضها البعض؟ لفئرة

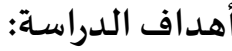

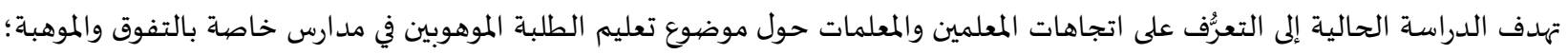
حيث تسعى الدراسة إلى تحقيق الأهداف التالية:

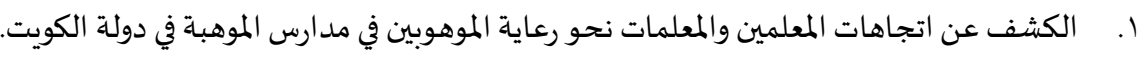

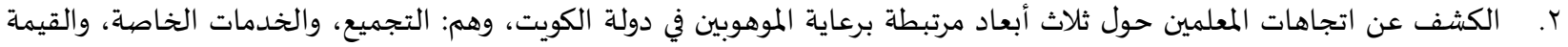

الاجتماعياة.

r. آ. التعرُّف على مستوى تفضيل المعلمين فيما يخص انتقال طلابهم الفائقين من فصولهم العادية إلى مدارس خاصة بالموهبة.

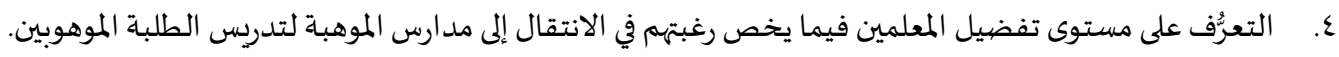

أهمية الدراسة:

تستمد الدراسة الحالية أهميتها من نتائجها، ومدى تأثير هذه النتائج في القائمين على تعليم الطلبة الموهوبين في دولة الكويت، فتتمثل أهمية

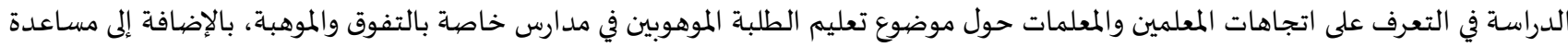

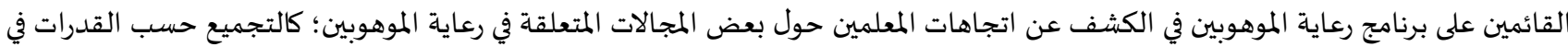
مدارس خاصة،، تقديم خدمات خاصة للمتفوقين، والقيمة الاجتماعية التي تعود على المجتمع من برنامج رعاية الموهوبين.

حدود الدراسة: الحدود الموضوعية: اقتصرت الدراسة على قياس اتجاهات معلمي ومعلمات المرحلة المتوسطة نحو رعاية الموهوبين في مدارس الموهبة وردود أفعالهم المادما

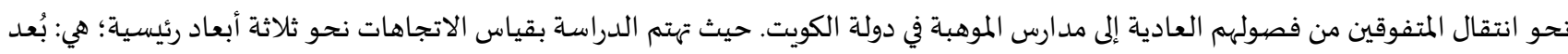
التجميع، وبُعد الخدمات والرعاية الخاصة، وبُعد القيمة الاجتماعية. الحدود البشرية: اقتصرت الدراسة على عينة من معلمي ومعلمات المرحلة المتوسطة في دولة الكويت.

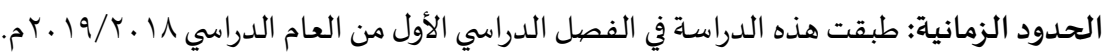


الحدود المكانية: طبقت أدوات البحث في ب ا مدرسة للمرحلة المتوسطة من مختلف المحافظات التعليمية في دولة الكويت.

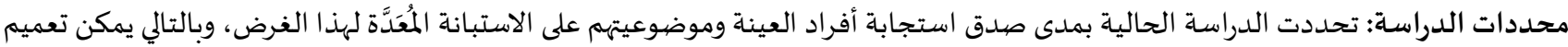

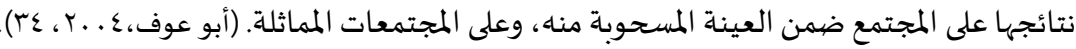

مصطلحات الدراسـة: التعريف الإجر ائي للطلبة الموهوبين: هم الطلبة الملتحقون بإحدى المدارس التابعة لمركز صباح الأحمد للموهبة والإبداع في دولة الكويت؛ علمًا بأههم ملتحقون بهذه المد ارس بناءً على معايير مركز صبباح الأحمد للموهبة والإبداع.

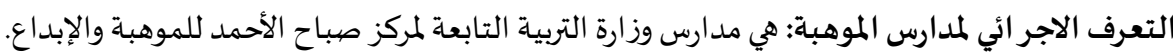

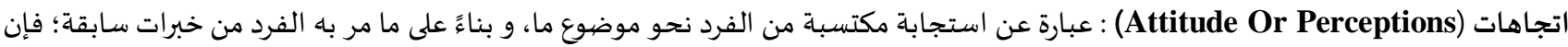

هذه الاستجابة ستكون إما إيجابية أو سلبية (Pickens, 2013)

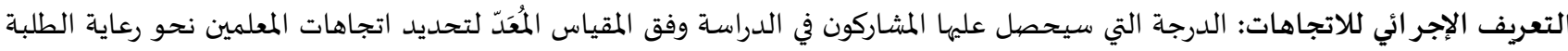
الموهوبين في مدارس الموهبة في دولة الكويت.

الطربقة والإجراءات: يتضمّن هذا الجزء وصفًا لمنهج الدراسة ومجتمعها وعينتها وأداة الدراسة المستخدَمة فيها وطرق التحقّق من صدق وثباتها، والمعالجة الإحصائية. منهج الدراسة: اعتمدت الدراسة على المنهج الوصفي التحليلي الارتباطي، والذي يسعى إلى دراسة توجهات المعلمين نحو مدارس الموهبة، ومدى ارتباطها مع

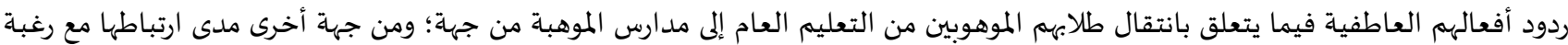
المعلمين أنفسهم في الانتقال إلى مدارس الموهبة لتدريس الموهوبين. مجتمع الدراسـة: تكون مجتمع الدراسة من جميع معلمي ومعلمات المرحلة المتوسطة العاملين في المدارس الحكومية في دولة الكويت للعام الدراسي

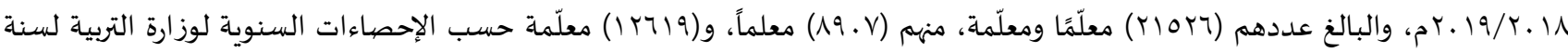

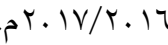
عينة الدراسـة: تكونت عينة الدراسة من (乏VV) معلّمًا ومعلّمة من المرحلة المتوسطة، ولم يتم حساب نسبة العينة من المجتمع الأصلي؛ لعدم توافر

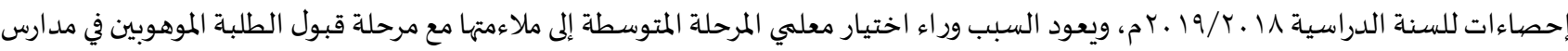
الموهبة؛ حيث يتم قبول الطلبة الموهوبين، ونقلهم إلى مدارس الموهبة مع بداية المرحلة المتوسطة من الصف الصف السادس. كما جرى اختيار أفراد العينة

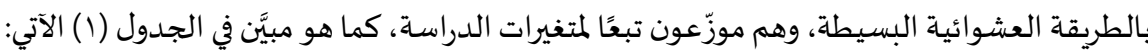

جدول(1) : توزيع عينة الدراسة تبعًا لمتغيراتها المستقلة

\begin{tabular}{|c|c|c|c|}
\hline النسبة المئوية & العدد & 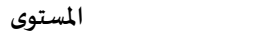 & المتغير \\
\hline $77, Y$ & 517 & ذكر & \multirow[t]{2}{*}{ الجنس } \\
\hline$r T, \Lambda$ & 171 & أنثى & \\
\hline$O V, \varepsilon$ & $T V \varepsilon$ & أقل من ـ ـ سنوات & \multirow[t]{3}{*}{ سنوات الخبرة } \\
\hline$r Y, V$ & 107 & من (. (- . . א) سنة & \\
\hline 9,9 & $\varepsilon V$ & أكثر من ·r سنة & \\
\hline 10,0 & $\varepsilon . \wedge$ & بكالوريوس & \multirow[t]{2}{*}{ المؤهل العلهي } \\
\hline $1 \varepsilon, 0$ & 79 & دراسات عليا & \\
\hline $10, r$ & $v r$ & لغة عربية & \multirow[t]{6}{*}{ الممادة العلمية } \\
\hline $10, \mathrm{~V}$ & vo & لغة إنجليزية & \\
\hline $1 T, \varepsilon$ & $7 \varepsilon$ & 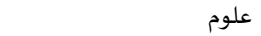 & \\
\hline ir & $\pi r$ & رياضيات & \\
\hline $1 ., 9$ & or & تربية إسلامية & \\
\hline $1 r, \lambda$ & 77 & دراسات اجتماعية & \\
\hline
\end{tabular}




\begin{tabular}{|c|c|c|}
\hline 0,9 & ru & حاسوب \\
\hline $0, V$ & TV & تربية فنية \\
\hline$r, 1$ & 1. & تربية موسيقية \\
\hline$\varepsilon, r$ & r. & تربية بدنية \\
\hline
\end{tabular}

أداة الدراسـة: - n

لتحقيق أهداف الدراسة تم إعداد استبانة حول توجهات المعلمين نحو رعاية الموهوبين بعد مراجعة الأدب التربوي والدراسات السابقة ذات

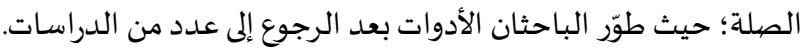
وتكونت أداة الدارسة الأولى من قسمين:

القسم الأول: عبارة عن المعلومات الديمغرافية للمشاركين (الجنس، الخبرة في التدريس، المؤهل العلمي، المادة الدراسية).

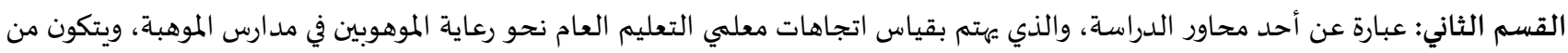

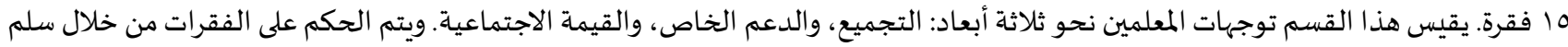

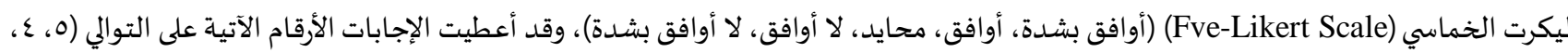

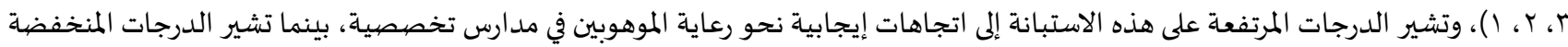

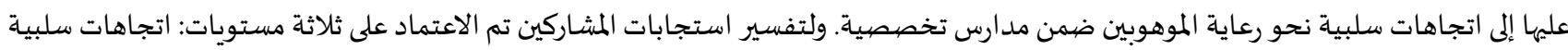

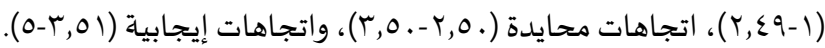
بالإضافة إلى ذلك، طوَّر الباحثان استبيانًا لقياس ردود الفعل العاطفية (Emotional Reaction) لدى المعان المعلمين والمعلمات على نهج مقاييس التفضيل السيمانتي أو الدلالي (Semantic Differential Scales)؛ حيث يسمح هذا الئان النوع من أنواع مقاييس الاتجاهات "بقياس اتجاه الأفراد نحو

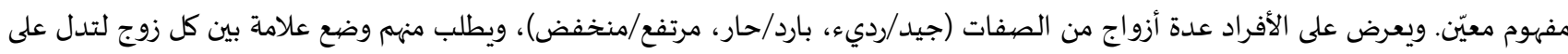

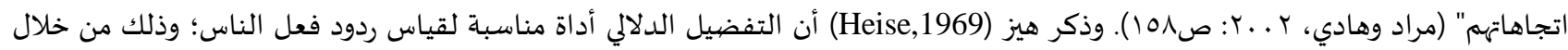
كلمات ومواقف تحفيزية بهدف الكشف عن المشاعر والعواطف؛ حيث إن المقياس ثنائي القطب يوجد على جانبيه صفات متناقضية يقع بينها رتَبَ يختار منها الفاحص.

في الدراسة الحالية، تتكون استبانة التفضيل الدلالي من قسمين؛ كما هو موضح في الفقرات التالية:

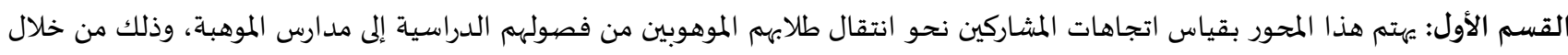

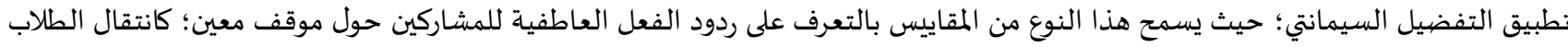

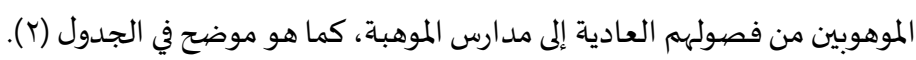

جدول (Y) : ردة الفعل العاطفية للمعلمين والمعلمات حول مستوى النشاط الطلابي

\begin{tabular}{|c|c|c|c|c|c|c|c|c|}
\hline & لمدراسية ............. & 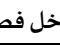 & لنشاط & 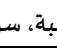 & 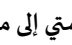 & لموهو. & عندما ينتقل & \\
\hline الصفة & بشكل كبيرجدًا & جدًّا & الشيء & عادي & بعضء & جدًا & جشكلَ كبير & الصفة \\
\hline قوي & V & 7 & 0 & $\varepsilon$ & r & r & 1 & ضعيف \\
\hline إيجابي & v & 7 & o & $\varepsilon$ & $r$ & $r$ & 1 & سلبي \\
\hline فعًَال & v & 7 & 。 & $\varepsilon$ & r & r & 1 & خامل \\
\hline تنافسي & v & 7 & 0 & $\varepsilon$ & $r$ & r & 1 & انسحابي \\
\hline مُحفِّز & v & 7 & 0 & $\varepsilon$ & r & r & 1 & مُحبط \\
\hline مُمْتِع & v & 7 & 0 & $\varepsilon$ & $r$ & r & 1 & 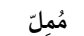 \\
\hline
\end{tabular}

كما هو واضح في الجدول السابق، يعبّر المفحوصون عن رد فعلهم حول الموقف من خلال مجموعة من الصفات المضادة ( Parallel

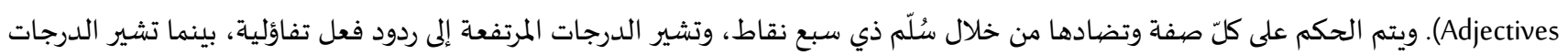


لمنخفضشة إلى ردود فعل تشاؤمياة. ولتفسير استجابات المشاركين تم الاعتماد على ثلاثة مستويات: ردود تشاؤمية (ا-ب)، ردود محايدة (1,r-0)، وردود

تفاؤليـة (V-0, (1).

القسم الثاني: يهتم هذا المحور بقياس اتجاهات المعلمين نحو انتقالهم من المدارس العامة إلى مدارس الموهبة لتدريس الطلاب الموهوبين؛ حيث تم

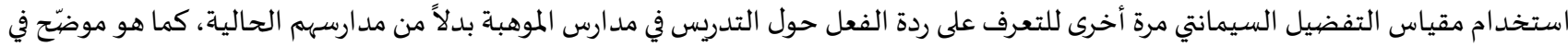

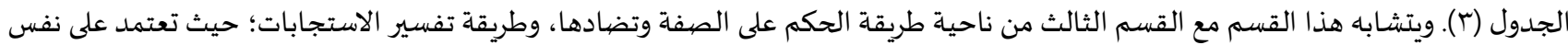

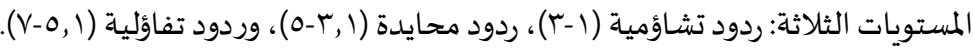

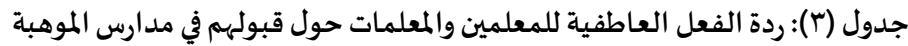

\begin{tabular}{|c|c|c|c|c|c|c|c|c|}
\hline & 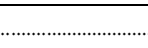 & ، سوف & ن عقليًَا & 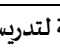 & لمتم في مد & شيحي & قف (Y): عند & \\
\hline الصفة & بشكل كبيرجدًا & جدًا & بعض الشيء & عادي & بعض & $r$ & جشدًا كبير & الصفة \\
\hline مرتاح & v & 7 & 0 & $\varepsilon$ & r & r & 1 & متوتر \\
\hline إيجابي & v & 7 & 0 & $\varepsilon$ & $r$ & r & 1 & سلبي \\
\hline و واثق & v & 7 & 0 & $\varepsilon$ & $r$ & r & 1 & مرتاب \\
\hline متفائل & v & 7 & 。 & $\varepsilon$ & $r$ & r & 1 & متشائم \\
\hline مطمئن & v & 7 & ० & $\varepsilon$ & r & r & 1 & قَلقِق \\
\hline راغب & v & 7 & 0 & $\varepsilon$ & $r$ & r & 1 & مُعرِض \\
\hline سعيد & v & 7 & 0 & $\varepsilon$ & r & r & 1 & حزين \\
\hline
\end{tabular}

صيدق وثبات أداة الدراسة: قام الباحثان بإجراء عدد من الخطوات لزيادة مصداقية أداة الدراسة؛؛ حيث تم إعداد الاستبيان بصورته الأولية، ومن ثم تم مقارنته ببعض الأدوات التي تم استخدامها لنفس الغرض وتدوين ملاحظات أولية. بعد ذلك تم تحكيمها مِن قِبَل ثلاثة مختصّين في مجال التفوق العقلي والتربية

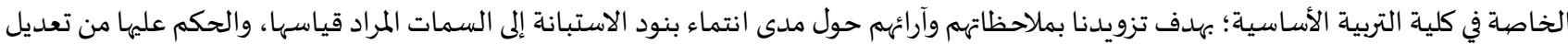
أو حذف أو إضيافة. وبعد إجراء عملية التحكيم، قام الباحثان في بعض التعديلات، وأهمها إلغاء مجال التسريع بجميع بنوده بسبب عدم تطبيقه في برنامج رعاية الموهوبين في دولة الكويت. أما فيما يخص ثبات الأداة، فقد قام الباحثان بحسـاب معامل الثبات للاختبار بطريقة الاتساق الداخلي بحسب معادلة كرونباخ ألفا

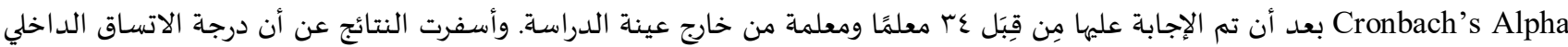

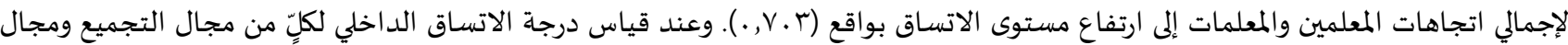

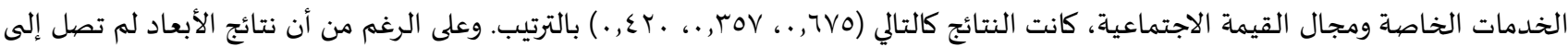

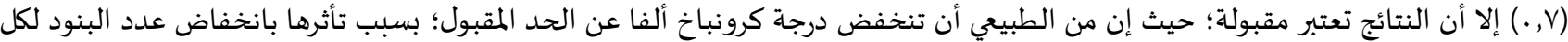

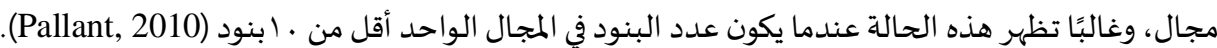

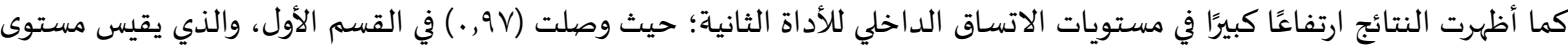
التفضيل المعلمين حول نقل طلابهم الفائقين إلى مدارس الموهبة، ووصلت إلى (ع و,.) في القسم الثاني والذي يقيس مستوى تفضيل المعلمين حول انتقالهم من مدارسهم العادية إلى مدارس الموهبة لتدريس الفيائقين.

إجراءات الدراسة:

ولتحقيق الأهداف المرجوة، والإجابة عن أسئلة الدراساة، اعتمد الباحثان على الإجراءات التالية: ا. . مراجعة الأدب النظري والدراسات السابقة ذات الصلة، والوقوف على نتائجها وتوصياتها وبحوثها المقترحة.

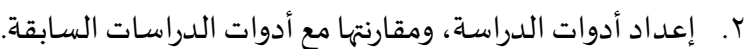
r. تحكيم الأدوات وتعديلها بعد مراجعة آراء المحكمين. 
ع. إجراء دراسة أولية Pilot Study على عينة مكونة من عَ معلّمًا ومعلّمة؛؛ وذلك بهدف حساب معامل الاتساق الداخلي، والتأكد من السلامة

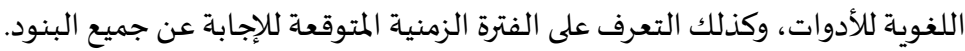

0. توزيع .7 نسخة ورقية على با مدرسة من مدارس المرحلة المتوسطة في مختلف محافظات دولة الكويت. وكانت نسبة الاستبانات العائدة

\% بو بواقع عVV

7. إدخال ومعالجة البيانات، واستخراج النتائج ومناقشتها.

المعالجة الإحصيائية:

استعان الباحثان بالرزمة الإحصائية للعلوم الاجتماعية (SPSS) لإجراء التحليلات والإحصاءات اللازمة لبيانات الاستبانة؛ حيث تم حساب

معامل الثبات للاختبار بطريقة الاتساق الداخلي بحسب معادلة كرونباخ ألفا Cronbach’s Alpha؛ وحساب كل من المتوسطات الحسابية

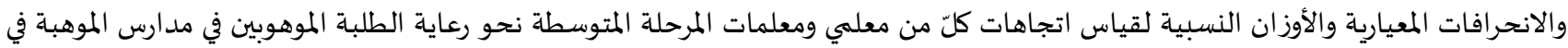
دولة الكويت. كما تم استخدام اختبار ت للعينة المستقلة Independent Samples T Test واختبار تحليل التباين الأحادي One-Way ANOVA؛ لمعرفة ما إذا كان هناك فروق بين متوسطات اتجاهات المعلمين والمعلمات، وردود أفعالهم حول مواقف تخصّ موضيوع الدراسة، وعلاقتها بكل من متغير الجنس والسنوات الخبرة والقسم العلمي. ومن ثَم إجراء اختبار بعدي Post-Hoc Test بهدف تحديد الفروق ذات الدلالة الإحصائية. كما تم حساب الارتباطات بين جميع الأبعاد المتعلقة باتجاهات المعلمين. كما استخدم الباحثان معامل ارتباط بيرسون correlation coefficient

عرض النتائج ومناقشتها:

يتناول هذا الجزء عرضًا لنتائج الدراسة ومناقشتها وفقًا لأسئلتها على النحو التالي: أولاً: للإجابة عن السؤال الأول ونصه: ما هي اتجاهات كلّ من معلمي ومعلمات المرحلة المتوسطة نحو رعاية الطلبة الموهوبين في مدارس الموهبة في دولة

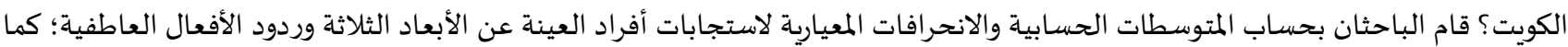
هو موضح بالجدول التالي.

\begin{tabular}{|c|c|c|c|c|c|}
\hline التقدير & $\begin{array}{c}\text { الانحراف المعياري } \\
\text { SD }\end{array}$ & المتوسط الحسابي & العدد & المجال & 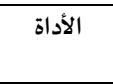 \\
\hline محايدة & ., ro & $r, \varepsilon 0$ & \multirow{6}{*}{$\varepsilon V \gamma$} & إجمالي الاتجاهات & \multirow[t]{4}{*}{ اتجاهات } \\
\hline محايدة &., 01 & $r, \Sigma 9$ & & التجميع & \\
\hline إيجابية & . T & $r, 70$ & & الخدمات الخاصة & \\
\hline محايدة &., $0 \varepsilon$ & $r, r)$ & & القيمة الاجتماعية & \\
\hline ردود محايدة & 1,09 & $r, \wedge \varepsilon$ & & انتقال الفائقين من الفصول العادية & \multirow[t]{2}{*}{ ردود الفعل } \\
\hline ردود تفاؤلية & $1, r 9$ & 0,01 & & انتقال المعلم إلى مدارس الموهبة & \\
\hline
\end{tabular}

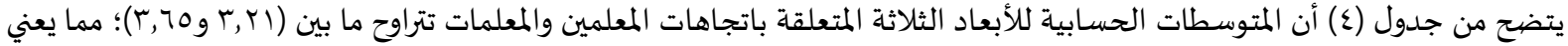

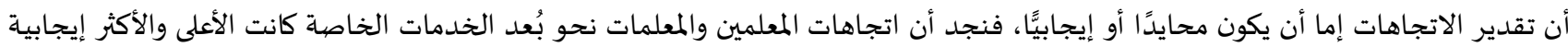
بمتوسط حسابي يبلغ (M=3.65)، بينما كانت استجاباتهم نحو البعد الأول والثاني حيادية؛ حيث إن المتوسط الحسابي لبعد التجميع يساوي

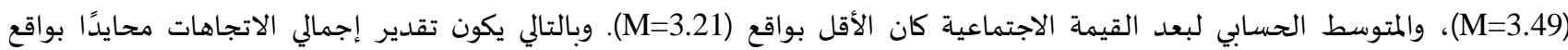
(M=3.45). وقد يُعزى ذلك إلى الخبرة السـابقة للمعلمين والمعلمات، وعلى سبيل الإيضاح نلاحظ أن المشاركين لديهم اتجاهات إيجابية حول تقديم

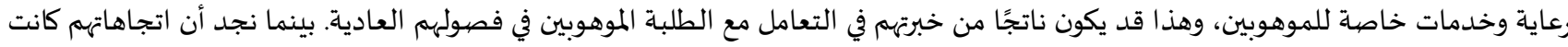

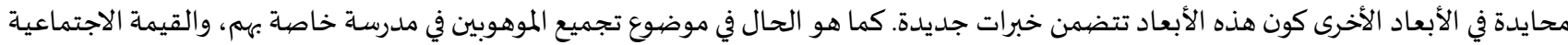

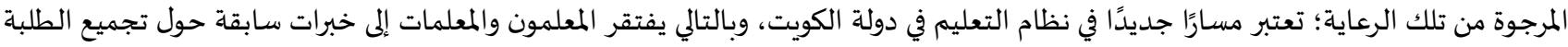

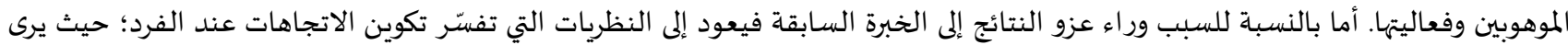
مجموعة من المنظرين في مجال الاتجاهات مثل (Kagan, 1992; Nespor, 1987; \& Thompson, 1992)، أن الاتجاهات(Perceptions) تتكون

نتيجة لتمازج بين المعتقدات (Beliefs) وبين الخبرات الواقعية أو الحقيقية (Factual Experience). 
ومن جهة أخرى، نلاحظ أن ردة فعل المعلمين والمعلمات حول انتقال الطلاب الموهوبين من مدارس عادية إلى مدارس الموهبة كانت أيضًا

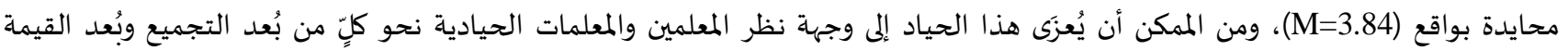

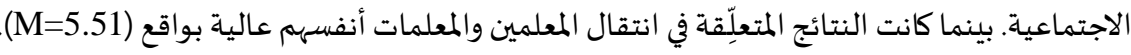

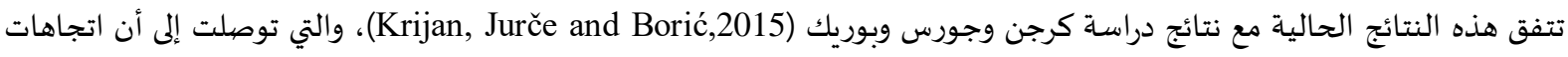

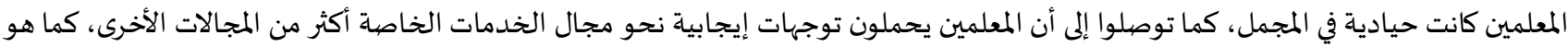

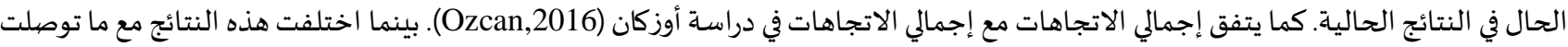

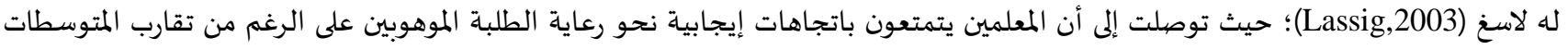

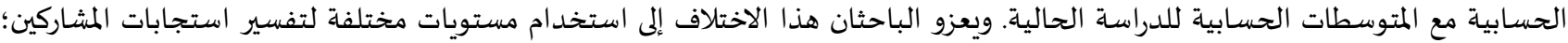

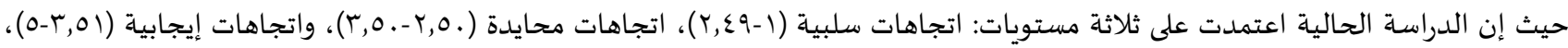

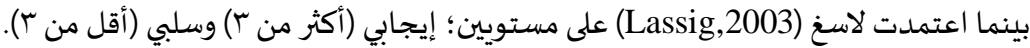

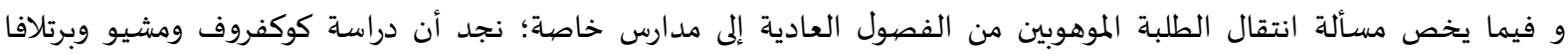
(Kočvarová, Machů, \& Bártlová, 2018)

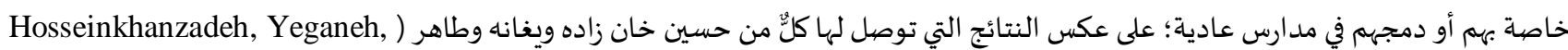

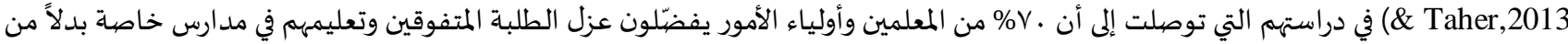

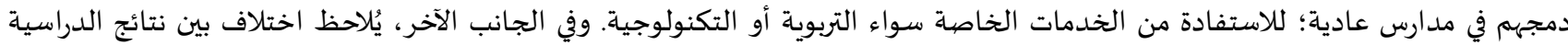
الحالية مع نتائج دراسة كلّ من أبو وأكانت وقوكدر (Abu, Akkanat \& Gökdere, 2017) التي توصلت إلى أن المعلمين لا يدعمون فكرة التحاد التجميع

وتقديم خدمات خاصية للموهوبين.

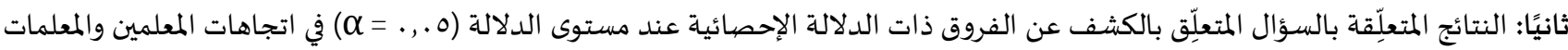

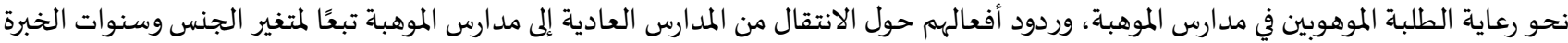
والقسم العلمي. بالنسبة إلى متغير الجنس. تم إجراء اختبار (ت) للعينة المستقلة Independent Samples T Test للكثف عن الفروق في متغير الجنس وجدول (o)

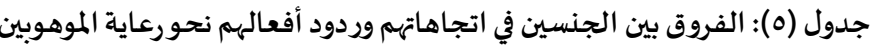

\begin{tabular}{|c|c|c|c|c|c|c|c|c|}
\hline الإحصيائية الدلالة & قيمة ت & درجة الحرية & $\begin{array}{c}\text { الانحراف المعياري } \\
\text { SD }\end{array}$ & $\begin{array}{c}\text { المتوسط الحسابي } \\
\text { M }\end{array}$ & العدد & الجنس & المجال & الأداة \\
\hline \multirow[t]{2}{*}{$\cdot, \mathrm{VA}$} & \multirow{2}{*}{$\cdot, \mathrm{r \Lambda}$} & \multirow[t]{2}{*}{$\varepsilon \vee 0$} & . & $r, \varepsilon_{0}$ & 117 & ذ كر & \multirow[t]{2}{*}{ إجمالي الاتجاهات } & \multirow[t]{8}{*}{ اتجاهات } \\
\hline & & & . ז人 & $r, \varepsilon \varepsilon$ & 171 & 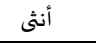 & & \\
\hline \multirow[t]{2}{*}{$\cdot, 9 \leq$} & \multirow{2}{*}{.,.$V Y$} & \multirow[t]{2}{*}{$\varepsilon V_{0}$} & $\cdot, \leqslant 9$ & $r, 0$. & $r 17$ & ذكر & \multirow[t]{2}{*}{ التجميع } & \\
\hline & & &., $0 \leqslant$ & $r, \varepsilon q$ & 171 & أنثى & & \\
\hline \multirow[t]{2}{*}{., 11} & \multirow[t]{2}{*}{1,09} & \multirow[t]{2}{*}{$\varepsilon V_{0}$} & . & $r, 7 \Lambda$ & $M 17$ & ذكر & \multirow[t]{2}{*}{ الخدمات الخاصة } & \\
\hline & & & $\cdot, 71$ & $r, 09$ & 171 & أنثى & & \\
\hline \multirow[t]{2}{*}{$|N|$} & \multirow[t]{2}{*}{ 1,rr- } & \multirow[t]{2}{*}{$\sum V_{0}$} & .,or & $r, 19$ & 117 & ذكر & \multirow[t]{2}{*}{ القيمة الاجتماعية } & \\
\hline & & &., $0 \mathrm{~V}$ & $r, r$ r & 171 & أنثى & & \\
\hline \multirow[t]{2}{*}{., rov } & \multirow[t]{2}{*}{. } & \multirow[t]{2}{*}{$r M \Lambda, O \Lambda$} & 1,01 & $r, q$. & $r 17$ & ذكر & \multirow{2}{*}{ 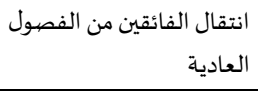 } & \multirow[t]{4}{*}{ ردود الفعل } \\
\hline & & & $1, V T$ & $r, v \varepsilon$ & 171 & أنثى & & \\
\hline \multirow[t]{2}{*}{, , . ** } & \multirow[t]{2}{*}{$r, 79$} & \multirow[t]{2}{*}{ 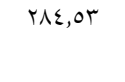 } & $1, r$. & 0,79 & $r 17$ & ذكر & \multirow{2}{*}{ الموهبة انتقال المعلم إلى مدارس } & \\
\hline & & & $1,0$. & $0,1 \mathrm{~V}$ & 171 & أنثى & & \\
\hline
\end{tabular}

*مستوى الدلالة الإحصيائية تساوي أو أقل من ه ., .

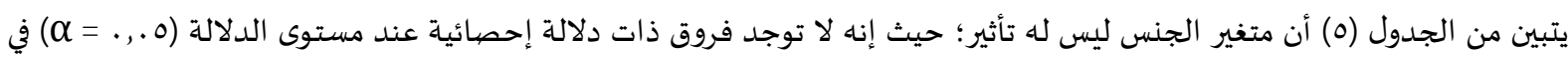

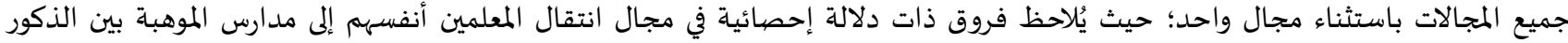

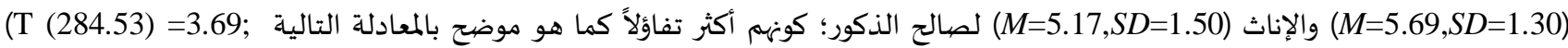
.000=ه، وقد يعزو الباحثان عدم وجود فروقات ذات دلالة إحصائية في معظم المجالات إلى المساواة المهنية المتبعة في وزارة التربية والتعليم بين

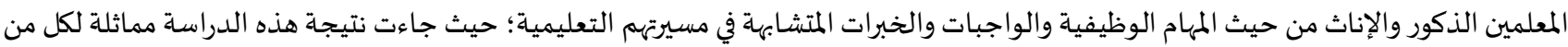
دراسة (خضير،، .. (Y)، ودراسة بيرسون (Persson,2014)، ودراسة تورتب وكنت (Tortop \& Kunt, 2013)؛ إلا أنَّ نتيجة الدراسة الحالية تختلف 
مع نتائج كلّ من كوكفروف ومشيو وبرتلافا (Kočvarová, Machů, \& Bártlová, 2018) التي توصلت إلى أن المعلّمات الإناث أكثر تأييدًا من المعلمين

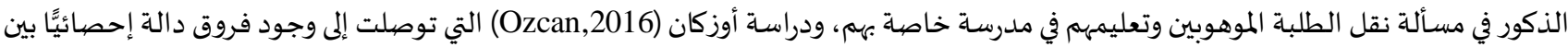

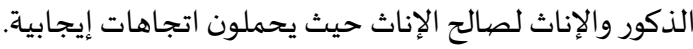

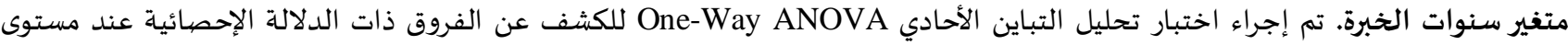

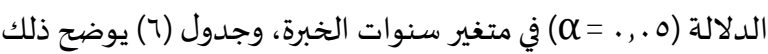

جدول (ך): اختبار تحليل التباين الأحادي بالنسبة لمتغيرسنوات الخبرة

\begin{tabular}{|c|c|c|c|c|c|}
\hline الدلالة الإحصائية & $\begin{array}{c}\text { اختبارف } \\
\text { F (2,474) }\end{array}$ & $\begin{array}{c}\text { الانحراف المعياري } \\
\text { SD }\end{array}$ & $\begin{array}{c}\text { المتوسط الحسابي } \\
\text { M }\end{array}$ & 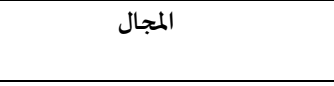 & 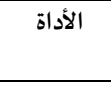 \\
\hline$\cdot, V Y$ & ., זrq & , ro & $r, \varepsilon 0$ & إجمالي الاتجاهات & \multirow[t]{4}{*}{ اتجاهات } \\
\hline., 01 & . $7 \vee 7$ &., 01 & $r, \varepsilon q$ & 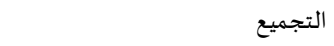 & \\
\hline$* ., ., 1$ & r,A & . & $r, 70$ & الخدمات الخاصة & \\
\hline$*_{.}, . \mathrm{rT}$ & r,人т &., $0 \leqslant$ & $r, r)$ & القيمة الاجتماعية & \\
\hline.,$r \varepsilon r$ & l, $\Sigma \mid \mathrm{V}$ & 1,09 & $r, \wedge \varepsilon$ & انتقال الموهوبين من الفصول العادية & \multirow[t]{2}{*}{ ردود الفعل } \\
\hline$* ., . \leqslant 0$ & r,וr. & $1, r q$ & 0,01 & انتقال المعلم إلى مدارس الموهبة & \\
\hline
\end{tabular}

"مستوى الدلالة الإحصائية تساوي أو أقل من ه. . .

يظهر الجدول (7) السابق فروقات دالة إحصائيًا في ثلاثة مجالات: يظهر الفرق الأول في مجال الخدمات الخاصة؛؛ حيث إن ف المحسوبة

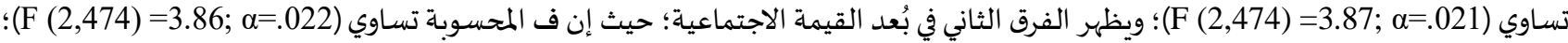
ويظهر الفرق الأخير في مجال انتقال المعلمين أنفسهم إلى مدارس الموهبة؛ حيث إن ف المحسوبة تساوي (F (F) (F) (2,474). ولمعرفة مصادر الفروق بين المجالات التي يظهر عندها دلالة إحصائية عند المستوى (0., = Q Q)، تم استخدام اختبار المقارنات البعدية Post-Hoc Test. وجدول (V) يوضيّ ذلك مع تفصيل لكل بُعد.

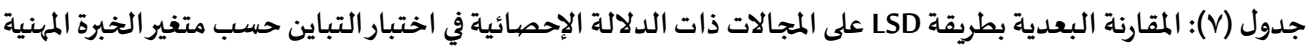

\begin{tabular}{|c|c|c|c|c|c|c|}
\hline $\begin{array}{c}\text { الإحصائية } \\
\text { Sig } \\
\end{array}$ & $\begin{array}{c}\text { الانتحراف } \\
\text { SD } \\
\end{array}$ & المتوسط الحسابي & السنوات الخبرة & $\begin{array}{c}\text { المتوسط الحسابي (الانحراف } \\
\text { المعياري) } \\
\text { M (SD) }\end{array}$ & سنوات الخبرة & 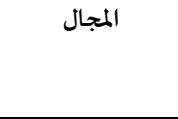 \\
\hline$* ., \ldots \wedge$ &., 70 & $r, 7 r$ & أقل من ـ ـ سنوات & \multirow[t]{2}{*}{ 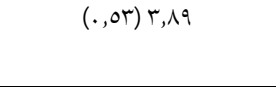 } & \multirow[t]{2}{*}{ أكثر من · r سنة } & \multirow[t]{2}{*}{ الخدمات الخاصة } \\
\hline$*_{.}, \ldots 9$ &., 01 & $r, \pi r$ & من (. (- . +Y) سنة & & & \\
\hline$*_{., \ldots 7}$ & .,or & r, ro & أقل من · ـ سنوات & \multirow[t]{2}{*}{$(., 0 \varepsilon) \Gamma, . .1$} & \multirow[t]{2}{*}{ أكثر من · r سنة } & \multirow[t]{2}{*}{ القيمة الاجتماعية } \\
\hline$*_{.}, ., r$. & .07 & r,tr & من (. (- . ب) سنة & & & \\
\hline$* ., .1 r$ & $1, r 9$ & $0, \varepsilon r$ & أقل من · ا سنوات & $(1, \Gamma \wedge) 0,9 \vee$ & أكثر من ·r سنة & انتقال المعلمين إلى \\
\hline
\end{tabular}

*مستوى الدلالة الإحصائية تساوي أو أقل من ه., ملرهاه

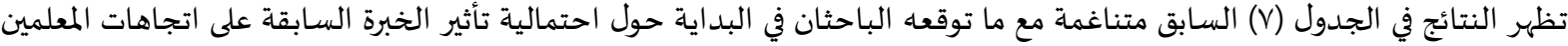

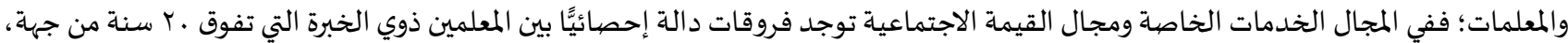

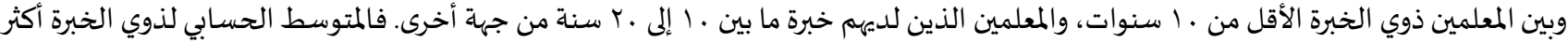

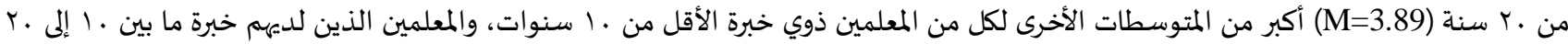
سنة (M=3.62; $\alpha=.009 ; M=3.63 ; \alpha=.008$ بالترتيب. بينما في مجال القيمة الاجتماعية، نلاحظ أن المتوسط الحسابي لمجموعة المعلمين ذوي

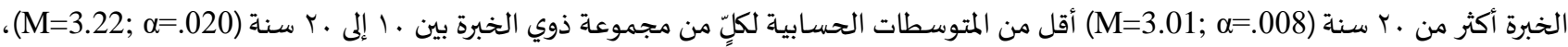
ومجموعة ذوي خبرة أقل من • إنوات(M=3.25; $\alpha=.006)$. . ويعزو الباحثان هذه النتائج إلى نفس السبب السابق؛ حيث يلاحظ أن ذوي الخبرة

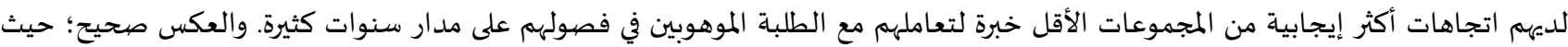

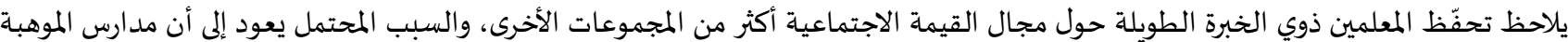
مشروع تربوي حديث التطوير، وبالتالي يصعب على المملمين تكوين اتجاهات مبنية على الخبرة المهنية حول القيمة المرجوة من تطبيق مدارس الموهبة. 
Kočvarová, Machů, ) وعند مقارنة النتائج الحالية مع مثيلاتها في دراسات أخرى، نجد أن هناك توافقًا جزئيًا بين نتيجة كوكفروف ومشيو وبرتلافا

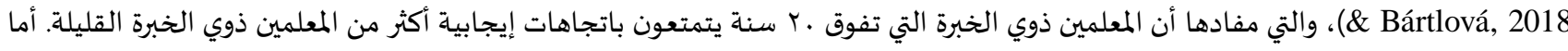

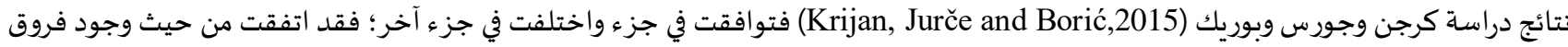

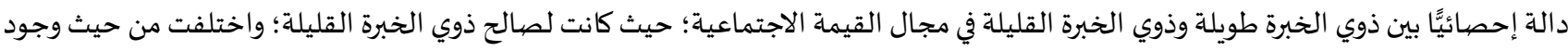

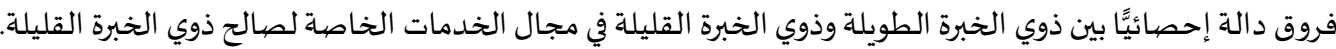

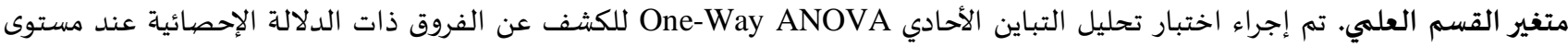
الدلالة (ه ., . = م) في متغير القسم العلمي، وجدول (م) يوضح ذلك.

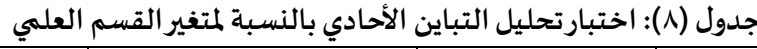

\begin{tabular}{|c|c|c|c|c|c|}
\hline الدلالة الإحصهائية & $\begin{array}{c}\text { اختبارف } \\
\text { F (9,467) }\end{array}$ & $\begin{array}{c}\text { الانحراف المعياري } \\
\text { SD }\end{array}$ & $\begin{array}{c}\text { المتوسط الحسابي } \\
\text { M }\end{array}$ & المجال & الأداة \\
\hline $1, \leqslant 0$ & 1,299 &., ro $_{0}$ & $r, \Sigma 0$ & إجمالي الاتجاهات & \multirow[t]{4}{*}{ اتجاهات } \\
\hline . ז^乏 & $1, .79$ &., 01 & $r, \varepsilon 9$ & 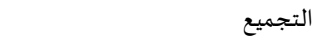 & \\
\hline$*_{., .}, \mathrm{r}$ & T, IAV & זT & $r, 70$ & الخدمات الخاصة & \\
\hline . $10 \varepsilon$ & $1, \varepsilon \vee 7$ & ., $0 \varepsilon$ & $r, r)$ & القيمة الاجتماعية & \\
\hline 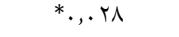 & $1,1.1$ & 1,09 & $r, \wedge \varepsilon$ & انتقال الفائقين من الفصول العادية & \multirow[t]{2}{*}{ ردود الفعل } \\
\hline . Tru & $1,1 \leqslant v$ & 1,49 & 0,01 & انتقال المملم إلى مدارس الموهبة & \\
\hline
\end{tabular}

*مستوى الدلالة الإحصائية تساوي أو أقل من ه . . .

يتضح من الجدول (^) وجود فروقات دالة إحصائيَّا في مجالين تُعزَى لمتغير القسم العلمي، وهم: مجال الخدمات الخاصة؛؛ حيث بلغت قيمة

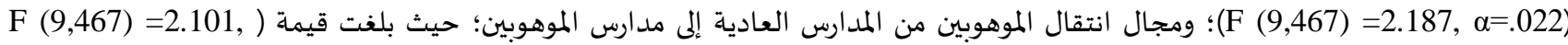
028.0 م). ولتفصيل النتائج السابقة، تم إجراء اختبار بَعدي Post-Hoc Test بهدف تحديد الفروق ذات الدلالة الإحصائية في المجالات السابقة. وجدول (9) يوضح ذلك مع تفصيل لكل بُعد.

\begin{tabular}{|c|c|c|c|c|c|c|}
\hline $\begin{array}{c}\text { الدلالة الإحصائية } \\
\text { Sig }\end{array}$ & $\begin{array}{c}\text { الانحراف } \\
\text { SD } \\
\text { SDياري }\end{array}$ & المتوسط الحسابي & الأقسام العلمية الأخرى & (الانحراف المعياري) & القسم العلمي & المجال \\
\hline$*, \pi r$ &., 07 & $r, V Y$ & رياضيات & \multirow[t]{4}{*}{$(., 7 \varepsilon) r, \varepsilon q$} & \multirow{4}{*}{ الاجتماعية الدراسات } & \multirow[t]{4}{*}{ الخدمات الخاصة } \\
\hline$* ., .1 \mathrm{~V}$ &., 7. & $r, v \varepsilon$ & لغة إنجليزية & & & \\
\hline${ }^{*}, \ldots r$ &., 09 & $r, q r$ & تربية فنية & & & \\
\hline${ }^{*} ., .11$ & ., & $r, 91$ & تربية موسيقية & & & \\
\hline${ }^{*} ., \ldots \Lambda$ & 1,77 & r, & علوم & \multirow[t]{4}{*}{$(1, r \cdot) \varepsilon, 01$} & \multirow[t]{4}{*}{ تربية فنية } & \multirow{4}{*}{ المدارس العادية الفائقين من } \\
\hline${ }^{*} ., . r T$ & $1, V T$ & $r, \mathrm{rA}$ & لغة إنجليزية & & & \\
\hline$* ., . r \varepsilon$ & 1,49 & $r, \mathrm{vV}$ & لغة عربية & & & \\
\hline$* ., \ldots r$ & $1,0$. & $r, 01$ & دراسات اجتماعية & & & \\
\hline
\end{tabular}

بعد إجراء اختبار المقارنات البعدية لكل مجال، تم اختيار أكثر قسم يحوي فروقات ذات دالة إحصائية لتباين تلك الفروقات مع الأقسام الأخرى؛ كما هو موضح في الجدول (9) السابق. ففي مجال الخدمات الخاصة،، يتضح أن المتوسط الحسابي لمعلمي أقسام الدراسات الاجتماعية هو

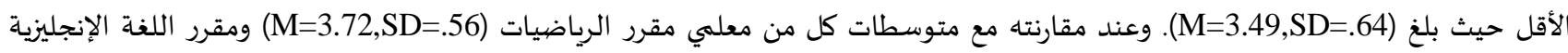
(M=3.74,SD=.60) ومقرر التربية الفنية (M=3.93,SD=.59) ومقرر التربية الموسيقية (M=3.98,SD=.94)، نجد أن هناك فروقات دالة إحصائيًا

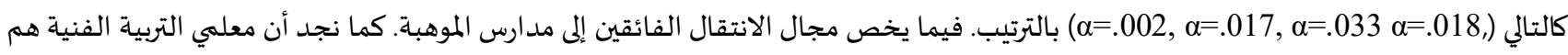
أكثر الداعمين لهذا التوجاء؛ حيث بلغ المتوسط الحسابي (M=4.58,SD=1.30) عند مقارنتها مع معلمي أقسام أخرى كالعلوم (M=3.62, a=.008)

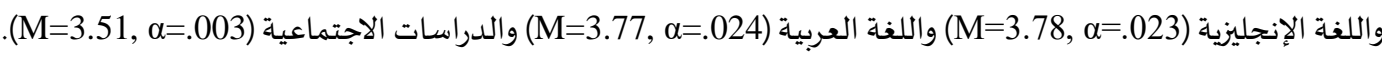

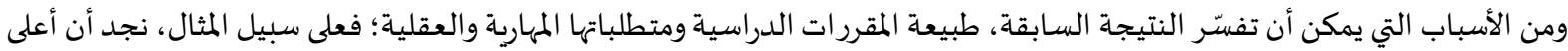
المتوسطات الحسابية تعود إلى معلمي مقررات التربية الفنية والتربية الموسيقية، والتي تتطلب في طبيعتها تطوير لمهارة التفكير الإبداعي ومهارة التخيل. 
وكذلك بالنسبة لمعلمي مقرر الرياضيات التي تتطلب مهارات عليا؛ كالتفكير المنطقي الرياضي، وبالمثل مقرر اللغة الإنجليزية، والذي يتطلب مهارات

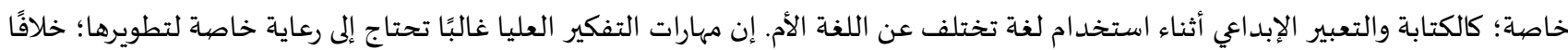

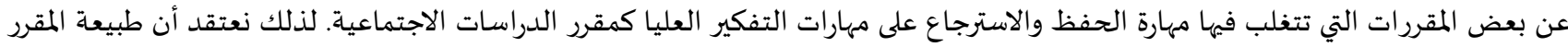

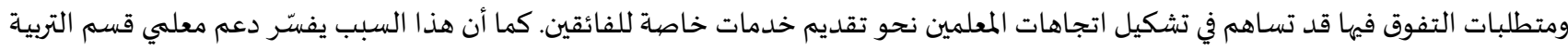

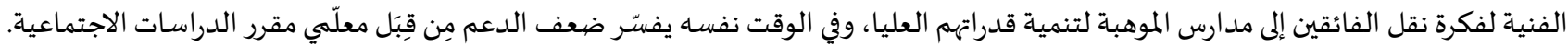

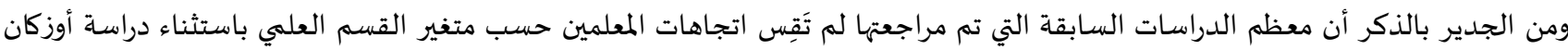
(Ozcan,2016)

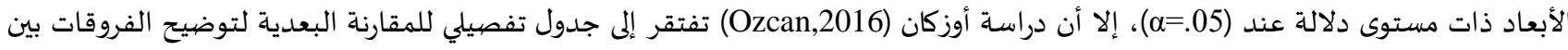
الأقسام العلمية.

ثالثًا: لمعرفة النتائج المتعلقة بالسؤال المتعلق بالعلاقات الارتباطية بين الأبعاد مع بعضها البعض وبين ردود الأفعال، تم استخدام معامل ارتباط بيرسون Pearson product-moment correlation coefficient

جدول (· (1): ارتباطات بيرسون ودلالاتها الإحصائية

\begin{tabular}{|c|c|c|c|c|c|c|c|}
\hline انتقال المعلمين & انتقال الفائقين & إجمالي الاتجاهات & القيمة الاجتماعية & الخدمات الخاصة & التجميع & & \\
\hline - & - & - & - & - & 1 & إرتباطئية بيرسونrدلالة & التجميع \\
\hline - & - & - & - & 1 & $\begin{array}{l}{ }^{* *} ., 01 \\
., \ldots\end{array}$ & $\begin{aligned} \text { r ارتباط بيرسئة إحصائية Sig } & \text { دلائة }\end{aligned}$ & الخدمات الخاصة \\
\hline - & - & - & 1 & $\begin{array}{c}{ }^{* *},, \text { ro9- } \\
\ldots, \ldots\end{array}$ & $\begin{array}{l}., .0 Y- \\
., \text { ro9 }\end{array}$ & 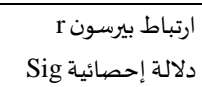 & القيمة الاجتماعية \\
\hline - & - & 1 & $\begin{array}{c}{ }^{* *} .,, r+q \\
\ldots, \ldots\end{array}$ & $\begin{array}{c}{ }^{* *},, \mathrm{~V} \uparrow \wedge \\
\ldots, \ldots\end{array}$ & $\begin{array}{l}{ }^{* *} ., \wedge .1 \\
., \ldots .\end{array}$ & 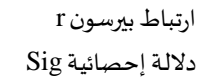 & إجمالي الاتجاهات \\
\hline - & 1 & $\begin{array}{l}{ }^{* *} ., 19 . \\
., \ldots\end{array}$ & $\begin{array}{c}{ }^{* *}, \text {, rา } \\
., \ldots\end{array}$ & $\begin{array}{c}{ }^{* *} ., \text {, } \\
\ldots, \ldots q\end{array}$ & $\begin{array}{c}{ }^{* *} ., \text {, } \\
\ldots, \ldots\end{array}$ & 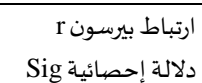 & انتقال الفائقين \\
\hline 1 & $\begin{array}{c}{ }^{* *} ., \text { rqА } \\
\ldots, \ldots\end{array}$ & $\begin{array}{l}\left.{ }^{* *} \cdot, r\right) . \\
\ldots, \ldots\end{array}$ & $\begin{array}{c}{ }^{* *},, 1 \leqslant \wedge- \\
., \ldots 1\end{array}$ & $\begin{array}{c}{ }^{* *},, \text {, YAr } \\
., \ldots\end{array}$ & $\begin{array}{c}{ }^{* *} ., r \varepsilon V \\
, \ldots\end{array}$ & $\begin{aligned} \text { r ارتباط بيرسونة إحصائية Sig } & \text { دلائة }\end{aligned}$ & انتقال المعلمين \\
\hline
\end{tabular}

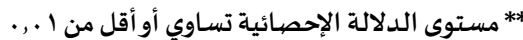

يشير الجدول (. () إلى وجود ارتباطات بين معظم المجالات، وتتراوح درجاتها بين صغير ومتوسطة وكبير. فعند النظر إلى إجمالي الاتجاهات

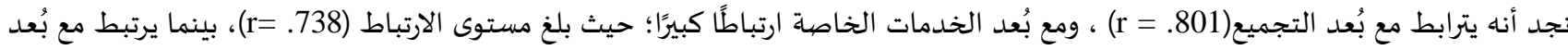

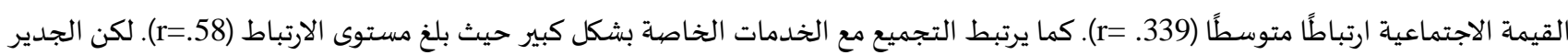

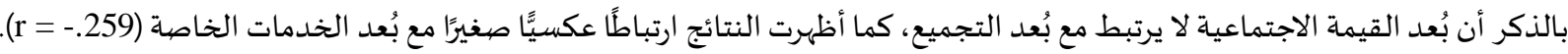

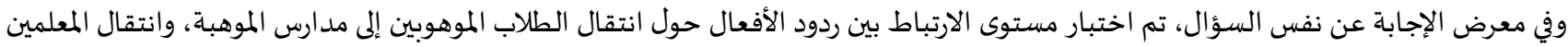

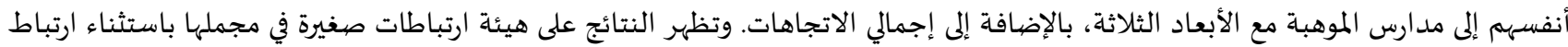

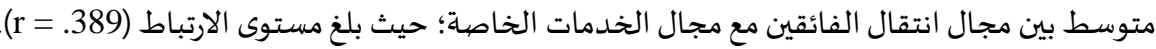
تتشابه النتائج الحالية في مجملها مع تلك التي ظهرت في دراسة كرجن وجورس وبوريك (Krijan, Jurče and Borić,2015)؛ حيث توصلت إلى الئ أن الن النيال

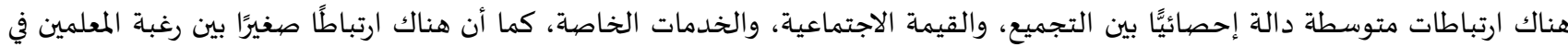
تدريس الموهوبين والخدمات الخاصة.

التوصيات:

يمكن استخلاص بعض التوصيات بناءً على النتائج التي تمًّ التوصل إلهها في هذه الدراسة من خلال النقاط التالية: ضرورة الربط وتبادل الخبرات ما بين معلمي مدارس الموهبة ومعلمي مدارس التعليم العام؛ لكسب خبرات جديدة في مجال رعاية الموهوبين. عَقد دورات وورش عمل وحلقات نقاش لمعلمي التعليم العام لاكتساب المعرفة، وتكوين اتجاهات إيجابية نحو رعاية الموهوبين. عَقد مناظرات بين مؤيدي الدمج الشامل لجميع الفئات، بما فههم الموهوبون، وبين معارضي فكرة دمج الموهوبين في المدارس العادية. تثقيف معلمي التعليم العام حول قضايا متعلقة في رعاية الموهوبين؛ كالتجميع والتسريع والإثراء، وغيرها من القضايا. 
توصي الدراسة الحالية بالكشف عن الأسباب والتبريرات وراء اتجاهات المعلمين نحو رعاية الطلبة الموهوبين في دولة الكويت، ومحاولة فهم

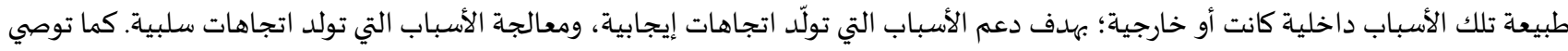

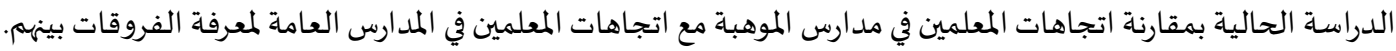

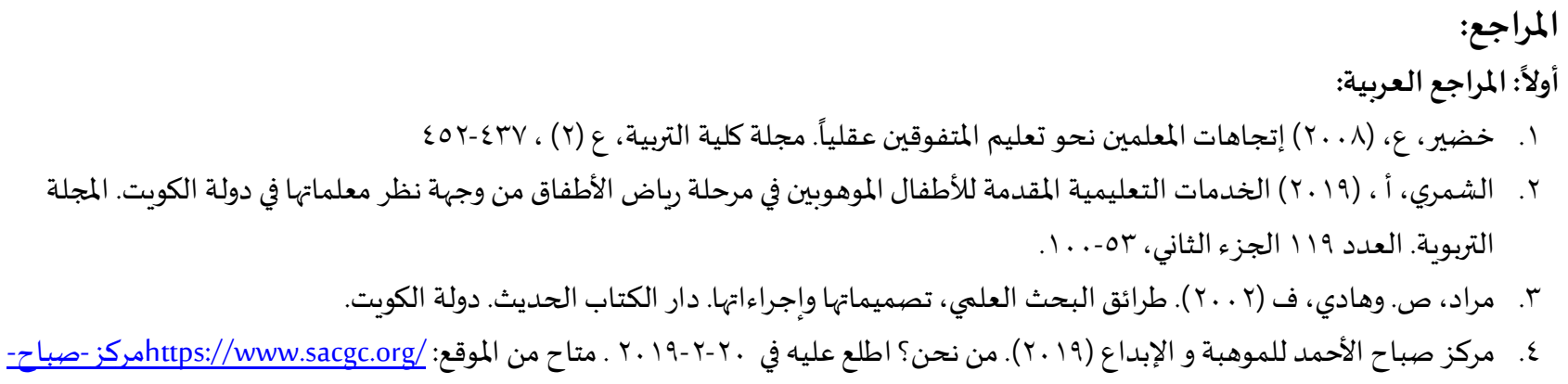

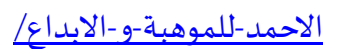

ثانياً: المراجع الأجنبية

[1] Abu. N., Akkanat. C. \& Gökdere. M., Teachers' Views about the Education of Gifted Students in Regular Classrooms, Turkish Journal of Giftedness and Education. 7(2) (2017), 87-109.

[2] Borland. J. H., Gifted education without gifted children: The case for no conception of giftedness. In R. J. Sternberg \& J. E. Davidson (Eds.), Conceptions of giftedness (2nd ed., pp. 1-19) (2005), New York, NY: Cambridge University Press.

[3] Gagné. F., \& Nadeau. L., Opinions about the gifted and their education. Montréal: GIREDT Center, Université du Québec á Montréal, (1991)

[4] Hosseinkhanzadeh. A ,Yeganeh. A; \& Taher. T., Investigate Attitudes of Parents and Teachers About Educational Placement of Gifted Students. Procedia - Social and Behavioral Sciences. 84(2013), 631636, https://doi.org/10.1016/j.sbspro.2013.06.616

[5] Heise. D. R., Some methodological issues in semantic differential research. Psychological Bulletin, 72(6) (1969), 406-422, http://dx.doi.org/10.1037/h0028448

[6] Kagan. D. M., Implications of research on teacher beliefs, Educational Psychologist. 27(1)(1992), 65-90.

[7] Kočvarová. E. Machů, \& Bártlová. N., Teachers' Preferences on the Issue of Segregation of Gifted Pupils in Czech Educational System. International Journal of Business, Human and Social Sciences,11.0(10) (2018), http://doi.org/10.5281/zenodo.1474815

[8] Kornblum. W., Sociologyina changing World. Harcourt Brace College Publishers, (1994)

[9] Lassig. C. J., Teachers' attitudes towards the gifted: the importance of professional development and school culture, Australasian Journal of Gifted Education, 18(2)(2009), 32-42.

[10] McCoach. D. B., \& Siegle. D., What Predicts Teachers' Attitudes Toward the Gifted?, Gifted child quarterly, 51(3)(2007), 246-254, https://doi.org/10.1177/0016986207302719

[11] Nespor. J., The role of beliefs in the practice of teaching, Journal of Curriculum Studies, 19(4)(1987), 317-328. 
[12] Neihart. M., The socioaffective impact of acceleration and ability grouping: Recommendation for best practice, Gifted Child Quarterly, 51(4)(2007), 330-341, https://doi.org/10.1177/0016986207306319

[13] Ozcan. D., Predictions and Attitudes towards Giftedness and Gifted Education, International journal of educational science. 15(1,2)(2016),126-133, https://doi.org/10.31901/24566322.2016/15.1-2.14

[14] Pajares. M.F., Teachers' beliefs and educational research: Cleaning up a messy construct, Review of Educational Research, 62(3)(1992), 307-332, https://doi.org/10.2307/1170741

[15] Perković Krijan. I., \& Borić. E., Primary School Teachers' Attitudes toward Gifted Students and differences in attitudes regarding the years of teaching, Croatian Journal of Education, 17(1) (2015), 165178.

[16] Pickens. J. (2013), Attitudes and perceptions, Journal of Personality and Social Psychology, 71 (2), 230 255.

[17] Polyzopoulou. K., Kokaridas. D., Patsiaouras. A. \& Gari. A., Teachers' perceptions toward education of gifted children in Greek educational settings, Journal of Physical Education and Sport, 14(2)(2014), 211 221.

[18] Ramos. E., Let us in: Latino Underrepresentation in gifted and talented programs, Journal of Cultural Diversity, 17(2010), 151-153.

[19] Reis. S. M., \& Renzulli. J. S., Is there still a need for gifted education? An examina- tion of current research. Learning and Individual Differences, 20(2010), 308-317, doi:10.1016/j. lindif.2009.10.012

[20] Renzulli. J. S., What makes giftedness? Reexamining a definition. Phi Delta Kappan, 60(1978), 180-184. doi:10.1177/003172171109200821

[21] Renzulli. J. S., The three-ring conception of giftedness: A developmental model for promoting creative productivity. In R. J. Sternberg \& J. E. Davidson (Eds.), Conceptions of giftedness (2nd ed., pp. 246279), (2005) New York, NY: Cambridge University Press.

[22] Riley. T. L., Teaching gifted students in the inclusive classroom. USA: Prufrock, (2011)

[23] Russell. J., High School Teachers' Perceptions of Giftedness, Gifted Education, and Talent Development, Journal of Advanced Academics, 29(4)(2018), 275-303, https://doi.org/10.1177/1932202x18775658

[24] Smith. C. M. M., Including the gifted and talented. Making inclusion work for more gifted and able learners. London and New York: Routledge, (2006)

[25] Thompson. Alba., Teachers' beliefs and conceptions: A synthesis of the research. In D. Grouws (Ed.), Handbook of research on mathematics teaching and learning (pp. 127-146), (1992), New York: Macmillan.

[26] Tortop. H., \& Kunt. K., International Online Journal of Educational Sciences, 5(2)(2013), 441-451.

[27] Troxclair. D. A, Preservice Teacher Attitudes Toward Giftedness. Roeper Review, 35(1)(2013), 58-64, https://doi.org/10.1080/02783193.2013.740603 


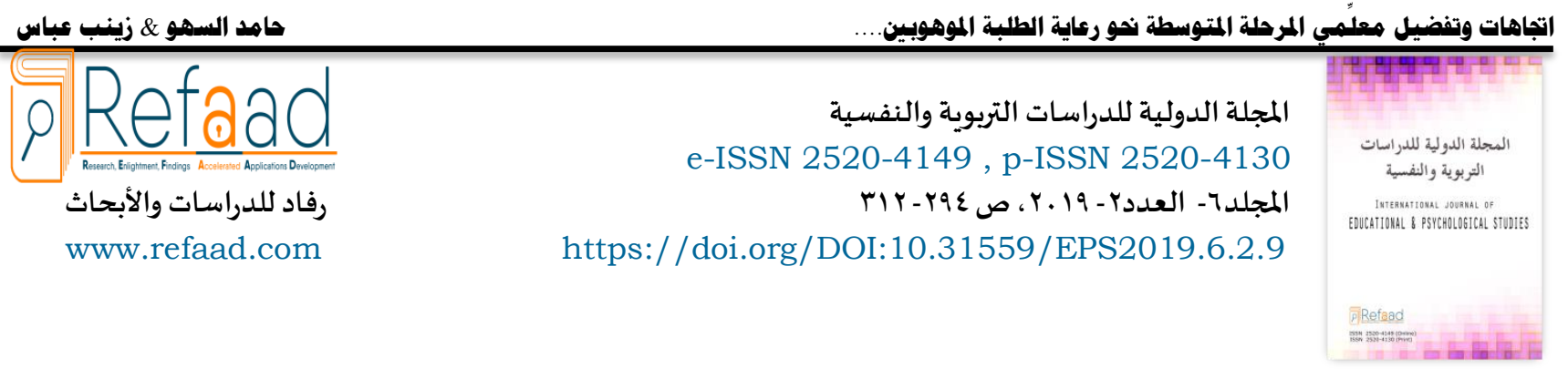

\title{
Intermediate School Teachers' Perceptions and Preferences on Nurturing Gifted Students in Gifted Schools in Kuwait
}

\author{
Hamed Jassim Alsahou \\ Assistant Professor, Special Education, College of Basic Education, Kuwait \\ dr.alsahou@ hotmail.com \\ Zainab Abbas \\ Associate Professor, Special Education, College of Basic Education, Kuwait \\ dr.zaenab@gmail.com
}

\begin{abstract}
This study aimed to measure the attitudes of middle school teachers towards nurturing talented students in gifted schools and their reactions to the transition of gifted students from their regular classes to gifted schools based on different variables such as gender, years of experience, and the scientific department in Kuwait. The study sample consisted of (477) middle school teachers, selected by a simple random approach. The researchers also adopted the descriptive analytical approach to suit the nature of the research, where the researchers developed a questionnaire that measures teachers' attitudes towards the fostering talented students which focuses on three dimensions or areas: aggregation (grouping), special services, and social value; also, they developed semantic deferential scale to understand the attitudes of teachers about the transition of their gifted students from their classes to gifted schools. The results showed that the attitudes and reactions of teachers about the transition of talented students from regular to gifted schools were generally neutral, while the results on the mobility of teachers themselves were high. The results also showed statistically significant differences attributable to the years of experience in favour of teachers with more than 20 years of experience. The results also showed statistically significant differences in the field of special services and the transfer of gifted students to gifted schools based on the scientific department. The gender variable has no effect in all areas except for the teachers themselves moving to talent schools for the benefit of males. Further discussion is highlighted followed by proposing some recommendations and putting forward some research ideas in this area.
\end{abstract}

Keywords: Gifted School; Gifted Studens; Perceptions; Ability Grouping; Special Services; Social Value

\section{References:}

[1] Abu. N., Akkanat. C. \& Gökdere. M., Teachers' Views about the Education of Gifted Students in Regular Classrooms, Turkish Journal of Giftedness and Education. 7(2) (2017), 87-109.

[2] Borland. J. H., Gifted education without gifted children: The case for no conception of giftedness. In R. J. Sternberg \& J. E. Davidson (Eds.), Conceptions of giftedness (2nd ed., pp. 1-19) (2005), New York, NY: Cambridge University Press.

[3] Gagné. F., \& Nadeau. L., Opinions about the gifted and their education. Montréal: GIREDT Center, Université du Québec á Montréal, (1991) 
[4] Hosseinkhanzadeh. A ,Yeganeh. A; \& Taher. T., Investigate Attitudes of Parents and Teachers About Educational Placement of Gifted Students. Procedia - Social and Behavioral Sciences. 84(2013), 631636, https://doi.org/10.1016/j.sbspro.2013.06.616

[5] Heise. D. R., Some methodological issues in semantic differential research. Psychological Bulletin, 72(6) (1969), 406-422, http://dx.doi.org/10.1037/h0028448

[6] Kagan. D. M., Implications of research on teacher beliefs, Educational Psychologist. 27(1)(1992), 65-90.

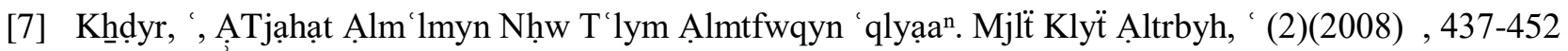

[8] Kočvarová. E. Machů, \& Bártlová. N., Teachers' Preferences on the Issue of Segregation of Gifted Pupils in Czech Educational System. International Journal of Business, Human and Social Sciences,11.0(10) (2018), http://doi.org/10.5281/zenodo.1474815

[9] Kornblum. W., Sociologyina changing World. Harcourt Brace College Publishers, (1994)

[10] Lassig. C. J., Teachers' attitudes towards the gifted: the importance of professional development and school culture, Australasian Journal of Gifted Education, 18(2)(2009), 32-42.

[11] McCoach. D. B., \& Siegle. D., What Predicts Teachers' Attitudes Toward the Gifted?, Gifted child quarterly, 51(3)(2007), 246-254, https://doi.org/10.1177/0016986207302719

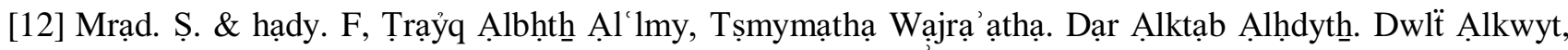
(2002)

[13] Mrkz Șbạh Ạlạ̉ḥmd Llmwhbh W ẠlạBdạ ' (2019). Mn Nḥn? Ạtl' 'lyh Fy 20-2-2019 . Mtạh Mn Ạlmwq': https://www.sacgc.org/mrkz-ṣbạh-ạlạhmọd-llmwhbh-w-ạlạbdạ “/

[14] Nespor. J., The role of beliefs in the practice of teaching, Journal of Curriculum Studies, 19(4)(1987), 317-328.

[15] Neihart. M., The socioaffective impact of acceleration and ability grouping: Recommendation for best practice, Gifted Child Quarterly, 51(4)(2007), 330-341, https://doi.org/10.1177/0016986207306319

[16] Ozcan. D., Predictions and Attitudes towards Giftedness and Gifted Education, International journal of educational science. 15(1,2)(2016),126-133, https://doi.org/10.31901/24566322.2016/15.1-2.14

[17] Pajares. M.F., Teachers' beliefs and educational research: Cleaning up a messy construct, Review of Educational Research, 62(3)(1992), 307-332, https://doi.org/10.2307/1170741

[18] Perković Krijan. I., \& Borić. E., Primary School Teachers' Attitudes toward Gifted Students and differences in attitudes regarding the years of teaching, Croatian Journal of Education, 17(1) (2015), 165178.

[19] Pickens. J. (2013), Attitudes and perceptions, Journal of Personality and Social Psychology, 71 (2), 230 255.

[20] Polyzopoulou. K., Kokaridas. D., Patsiaouras. A. \& Gari. A., Teachers' perceptions toward education of gifted children in Greek educational settings, Journal of Physical Education and Sport, 14(2)(2014), 211 221.

[21] Ramos. E., Let us in: Latino Underrepresentation in gifted and talented programs, Journal of Cultural Diversity, 17(2010), 151-153. 
[22] Reis. S. M., \& Renzulli. J. S., Is there still a need for gifted education? An examina- tion of current research. Learning and Individual Differences, 20(2010), 308-317, doi:10.1016/j. lindif.2009.10.012

[23] Renzulli. J. S., What makes giftedness? Reexamining a definition. Phi Delta Kappan, 60(1978), 180-184. doi: $10.1177 / 003172171109200821$

[24] Renzulli. J. S., The three-ring conception of giftedness: A developmental model for promoting creative productivity. In R. J. Sternberg \& J. E. Davidson (Eds.), Conceptions of giftedness (2nd ed., pp. 246279), (2005) New York, NY: Cambridge University Press.

[25] Riley. T. L., Teaching gifted students in the inclusive classroom. USA: Prufrock, (2011)

[26] Russell. J., High School Teachers' Perceptions of Giftedness, Gifted Education, and Talent Development, Journal of Advanced Academics, 29(4)(2018), 275-303, https://doi.org/10.1177/1932202x18775658

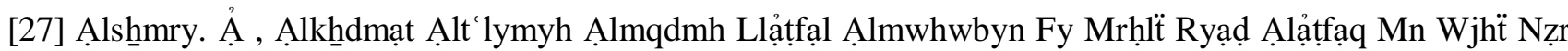
M'lmạthạ Fy Dwlẗ Ạlkwyt, Ạlmjlh Ạltrbwyh, Ạl'dd 119 Ạljz' Ạlthạny, (2019) 53-100

[28] Smith. C. M. M., Including the gifted and talented. Making inclusion work for more gifted and able learners. London and New York: Routledge, (2006)

[29] Thompson. Alba., Teachers' beliefs and conceptions: A synthesis of the research. In D. Grouws (Ed.), Handbook of research on mathematics teaching and learning (pp. 127-146), (1992), New York: Macmillan.

[30] Tortop. H., \& Kunt. K., International Online Journal of Educational Sciences, 5(2)(2013), 441-451.

[31] Troxclair. D. A, Preservice Teacher Attitudes Toward Giftedness. Roeper Review, 35(1)(2013), 58-64, https://doi.org/10.1080/02783193.2013.740603 